\title{
pH-Dependent Electron Transfer from Re-bipyridyl Complexes to Metal Oxide Nanocrystalline Thin Films
}

\author{
Chunxing She, ${ }^{\dagger}$ Neil A. Anderson, ${ }^{\dagger}$ Jianchang Guo, ${ }^{\dagger}$ Fang Liu,,${ }^{\ddagger}$ Wan-Hee Goh, ${ }^{\dagger}$ Dai-Tao Chen, ${ }^{\dagger}$ \\ Debra L. Mohler, ${ }^{\dagger}$ Zhong-Qun Tian, ${ }^{\S}$ Joseph T. Hupp,*, and Tianquan Lian*, \\ Department of Chemistry, Emory University, Atlanta, Georgia 30322, Department of Chemistry, Northwestern \\ University, Evanston, Illinois 60208, and State Key Laboratory for Physical Chemistry of Solid Surfaces, \\ Xiamen University, Xiamen 361005, China
}

Received: July 18, 2005; In Final Form: August 20, 2005

\begin{abstract}
Photoinduced interfacial electron transfer (ET) from molecular adsorbates to semiconductor nanoparticles has been a subject of intense recent interest. Unlike intramolecular ET, the existence of a quasicontinuum of electronic states in the solid leads to a dependence of ET rate on the density of accepting states in the semiconductor, which varies with the position of the adsorbate excited-state oxidation potential relative to the conduction band edge. For metal oxide semiconductors, their conduction band edge position varies with the $\mathrm{pH}$ of the solution, leading to $\mathrm{pH}$-dependent interfacial ET rates in these materials. In this work we examine this dependence in $\mathrm{Re}\left(\mathrm{L}_{\mathrm{P}}\right)(\mathrm{CO})_{3} \mathrm{Cl}$ (or ReC1P) $\left[\mathrm{L}_{\mathrm{P}}=2,2^{\prime}\right.$-bipyridine-4,4'-bis- $\left.\mathrm{CH}_{2} \mathrm{PO}(\mathrm{OH})_{2}\right]$ and Re$\left(\mathrm{L}_{\mathrm{A}}\right)(\mathrm{CO})_{3} \mathrm{Cl}$ (or ReC1A) $\left[\mathrm{L}_{\mathrm{A}}=2,2^{\prime}\right.$-bipyridine-4,4'-bis- $\mathrm{CH}_{2} \mathrm{COOH}$ ] sensitized $\mathrm{TiO}_{2}$ and $\mathrm{ReC1P}$ sensitized $\mathrm{SnO}_{2}$ nanocrystalline thin films using femtosecond transient IR spectroscopy. ET rates are measured as a function of $\mathrm{pH}$ by monitoring the $\mathrm{CO}$ stretching modes of the adsorbates and mid-IR absorption of the injected electrons. The injection rate to $\mathrm{TiO}_{2}$ was found to decrease by 1000 -fold from $\mathrm{pH} 0-9$, while it reduced by only a factor of a few to $\mathrm{SnO}_{2}$ over a similar $\mathrm{pH}$ range. Comparison with the theoretical predictions based on Marcus' theory of nonadiabatic interfacial ET suggests that the observed pH-dependent ET rate can be qualitatively accounted for by considering the change of density of electron-accepting states caused by the $\mathrm{pH}$-dependent conduction band edge position.
\end{abstract}

\section{Introduction}

Photoinduced interfacial electron transfer (ET) between molecular adsorbates and semiconductor nanoparticles has been a subject of intense recent interest. ${ }^{1,2}$ Many recent studies are motivated by its relevance to a dye-sensitized solar cell, in which the rates of charge injection from a molecular excited state to metal oxide nanocrystalline thin films and subsequent recombination play key roles in determining the device efficiency. ${ }^{3,4}$ More recently, the connection between ET rate at a moleculeelectrode junction and its conductance was also formulated, suggesting that understanding factors controlling interfacial ET dynamics can also provide useful insight for designing molecular electronics. ${ }^{5-7}$

A fundamental difference between interfacial and inter-/ intramolecular ET is the existence of a quasicontinuum of electronic states in the solid. The driving force of ET to these states varies with their energy, covering the normal, barrierless, and inverted regimes simultaneously for a given adsorbate potential. In the nonadiabatic limit, the total ET rate is the sum of rates of these parallel pathways, giving rise to the dependence of ET rate on the density of states (DOS) in the solid. ${ }^{8-11}$ For a semiconductor, the density of conduction band states increases with the square root of energy for states near and above the conduction band edge, and the variation is rapid below the band

\footnotetext{
* Corresponding authors. E-mail: tlian@emory.edu (T.L.); jthupp@ chem.northwestern.edu (J.T.H.)

Department of Chemistry, Emory University.

Department of Chemistry, Northwestern University.

$\S$ State Key Laboratory for Physical Chemistry of Solid Surfaces, Xiamen University.
}

edge, where it is often modeled as an exponential tail for materials with large defect density. ${ }^{12}$ This dependence is expected to lead to a variation of ET rate with the relative position of the adsorbate potential with respect to the conduction band edge.

A unique feature of metal oxide semiconductors, such as $\mathrm{TiO}_{2}, \mathrm{SnO}_{2}, \mathrm{ZrO}_{2}$, and $\mathrm{ZnO}$, is the dependence of conduction band edge position on the $\mathrm{pH}$ of the solution according to the Nernst-like equation: ${ }^{13-19}$

$$
E_{\mathrm{cb}}(\mathrm{pH})=E_{\mathrm{cb}}(\mathrm{pH} 0)-0.059 * \mathrm{pH}
$$

The most extensively studied is $\mathrm{TiO}_{2}$, which exhibits Nernstian behavior over a very wide range of $\mathrm{pH}$ ( $\log$ (proton activity) from -8 to +23 ), but is independent of proton activity beyond these limits. ${ }^{16}$ In part on the basis of spectroelectrochemical and quartz crystal microgravimetric studies of nanocrystalline $\mathrm{TiO}_{2}$ showing potential dependent proton uptake near and at $E_{\mathrm{cb}}$, the $\mathrm{pH}$ dependence appears to be associated with oxidation-statedependent protonation/deprotonation of Ti(IV/III) surface states. (Note that even carefully prepared single crystals necessarily contain a finite number of defects and surface states.)

A second contribution is independent of surface state redox behavior and comes from variation of surface charge with $\mathrm{pH}$ caused by the $\mathrm{H}^{+}$adsorption/desorption equilibrium. The magnitude of this contribution is given by the $\zeta$ potential and is typically determined electrophoretically by using metal oxide particles in a $\mathrm{pH}$-gradient gel. ${ }^{20}$ The $\zeta$ potential contribution is zero at the $\mathrm{pH}$ of zero charge (pzc, $\sim 4.5$ for titanium dioxide $^{20,21}$ ), but can amount to several tens of millivolts a few 
$\mathrm{pH}$ units above or below the pzc. Beyond this range, the $\zeta$ potential becomes $\mathrm{pH}$ independent because the surface is either fully protonated (low $\mathrm{pH}$ ) or fully deprotonated (high $\mathrm{pH}$ ), i.e., the surface charge no longer changes significantly with $\mathrm{pH}$. While the $\zeta$ potential contribution is comparatively small, it is important because it can influence the redox potentials of surface-attached compounds via a classic diffuse double-layer effect. Redox sites located very close to the surface (or more precisely, the outer Helmholtz plane) experience a larger fraction of the $\zeta$ potential and so will show a greater variation with $\mathrm{pH}$ than ones positioned further from the interface. Several examples of variations in redox potentials with $\mathrm{pH}$, near the $\mathrm{pzc}$, have been reported. ${ }^{22,23}$ The most extensive study is one by Gaal and Hupp, who examined a $\mathrm{TiO}_{2}$-attached bipyridyl iron(III/II) couple over a $13 \mathrm{pH}$ unit range. ${ }^{23}$ In agreement with other reports, ${ }^{22}$ they observed changes in $\mathrm{Fe}(\mathrm{III} / \mathrm{II})$ potential of about $-17 \mathrm{mV}$ per $\mathrm{pH}$ unit for $\mathrm{pH}$ values within a few units either side of the pzc, but no changes at more extreme pHs. Over a broader range, they observed a sigmoidal dependence of redox potential on $\mathrm{pH}$ that agreed closely with independent measures of the $\mathrm{pH}$ dependence of the $\mathrm{TiO}_{2} \zeta$ potential.

The $\mathrm{pH}$ dependence of the conduction band edge is expected to lead to a $\mathrm{pH}$-dependent interfacial electron transfer rate. Early studies of photocurrent in dye-sensitized metal oxide electrodes show retardation of photocurrent at higher $\mathrm{pH}$, consistent with a slowing down of injection rates. ${ }^{15,24,25}$ However, the overall cell photocurrent depends on the rates of many processes, including both the electron injection from the adsorbate excited state to semiconductor and the subsequent recombination of the injected electrons with the adsorbate cation, both of which are affected by $\mathrm{pH}$, and most likely in different ways, as demonstrated in a recent study of porphyrin-sensitized $\mathrm{TiO}_{2}$ nanocrystalline thin-film electrode. ${ }^{26}$ To clearly understand the dependence of photocurrent on $\mathrm{pH}$, direct measurements of the effect on injection and recombination processes are needed.

The effect of $\mathrm{pH}$ on back ET kinetics in different semiconductor/dye systems has been studied in recent years. ${ }^{27-29}$ The back ET rate was found to be independent of $\mathrm{pH}$ for $\mathrm{Ru}(\mathrm{L})_{3}[\mathrm{~L}$ $=2,2^{\prime}$-bipyridine-4,4'-( $\left.\left.\mathrm{CH}_{2} \mathrm{PO}\left(\mathrm{OCH}_{2} \mathrm{CH}_{3}\right)_{2}\right)_{2}\right]$ sensitized $\mathrm{TiO}_{2}$ nanocrystalline systems. ${ }^{27}$ However, for another ET system with electrostatically attached $\mathrm{Ru}$ and Os bipyridyl complexes on $\mathrm{SnO}_{2}$, back ET rates change with $\mathrm{pH}$, tracking the variation of driving force caused by the $\mathrm{pH}$-dependent band edge. ${ }^{30}$ It should be noted that back ET kinetics is controlled by the rate of ET from trap states to the oxidized adsorbate as well as the electron hopping rate in the nanocrystals. ${ }^{31-34}$ While the rate of the ET process is expected to vary sensitively with $\mathrm{pH}$ because of its dependence on driving force, the effect of $\mathrm{pH}$ on the hopping process is less clear. This complex mechanism may be responsible for the complex $\mathrm{pH}$ dependence in the back ET kinetics reported so far.

The effect of $\mathrm{pH}$ on the electron injection processes has also been examined. $\mathrm{Qu}$ and Meyer have shown that $\mathrm{pH}$ treatment of nanocrystalline $\mathrm{TiO}_{2}$ film affects the injection quantum yield. ${ }^{35}$ More recently, Asbury and co-workers directly measured the $\mathrm{pH}$-dependent injection kinetics in $\mathrm{Ru}(\mathrm{dcbpy})_{2}(\mathrm{X})_{2}$ [dcbpy $=2,2^{\prime}$-bipyridine-4,4'-bis-COOH, $(\mathrm{X})_{2}=2 \mathrm{NCS}^{-}, 2 \mathrm{CN}^{-}$, and dcbpy] sensitized $\mathrm{TiO}_{2}$ nanocrystalline thin film. ${ }^{36}$ The injection kinetics was found to be biphasic with a $<100$ fs component and a slower nonexponential component. Although it was demonstrated that both the amplitude of the fast component and the rate of the slow component decreased with $\mathrm{pH}$, the ultrafast injection rate and the associated cooling of hot injected electrons have hindered a quantitative examination of the $\mathrm{pH}$ dependence.
CHART 1: Structures of $\operatorname{ReC1A}(\mathrm{R}=\mathrm{COOH})$ and $\operatorname{ReC1P}\left(\mathbf{R}=\mathbf{P O}_{3} \mathrm{H}_{2}\right)$.

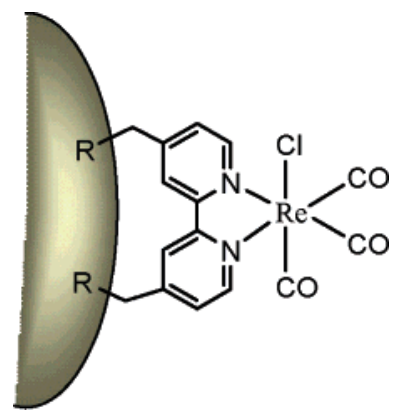

In this work, we examined the $\mathrm{pH}$ dependence of injection rate in $\mathrm{Re}\left(\mathrm{L}_{\mathrm{P}}\right)(\mathrm{CO})_{3} \mathrm{Cl}$ (or $\mathrm{ReC} 1 \mathrm{P}$ ) $\left[\mathrm{L}_{\mathrm{P}}=2,2^{\prime}\right.$-bipyridine-4,4'bis- $\left.\mathrm{CH}_{2} \mathrm{PO}(\mathrm{OH})_{2}\right]$ and $\mathrm{Re}\left(\mathrm{L}_{\mathrm{A}}\right)(\mathrm{CO})_{3} \mathrm{Cl}$ (or $\mathrm{ReC} 1 \mathrm{~A}$ ) $\left[\mathrm{L}_{\mathrm{A}}=2,2^{\prime}-\right.$ bipyridine-4,4'-bis- $\left.\mathrm{CH}_{2} \mathrm{COOH}\right]$ sensitized $\mathrm{TiO}_{2}$ and $\mathrm{ReC} 1 \mathrm{P}$ sensitized $\mathrm{SnO}_{2}$ nanocrystalline thin films (see Chart 1). Unlike the $\mathrm{Ru}(\mathrm{dcbpy})_{2}(\mathrm{X})_{2}$ complexes examined in the previous study, $\mathrm{ReC} 1 \mathrm{P}$ and $\mathrm{ReC} 1 \mathrm{~A}$ have a $\mathrm{CH}_{2}$ unit inserted between the bipyridine and the anchoring groups, slowing down electron injection rate. ${ }^{37-41}$ In these systems, the $<100$ fs injection component is negligible and only the slow injection component from the relaxed ${ }^{3}$ MLCT excited state is observed. Furthermore, in addition to the IR absorption of the injected electrons, the $\mathrm{CO}$ stretching bands of the adsorbate can also be simultaneously monitored to fully determine the injection rate and yield. We observed a retardation of electron injection rate by 3 orders of magnitude from $\mathrm{pH} 0-9$ in $\mathrm{TiO}_{2}$ films, and much smaller variation in $\mathrm{SnO}_{2}$ films. These dependences were compared with theoretical predictions on the basis of Marcus' theory of nonadiabatic interfacial ET.

\section{Experimental Section}

Femtosecond IR Spectrometer. The femtosecond IR spectrometer used in these experiments was based on an amplified femtosecond Ti:sapphire laser system (coherent Vitesse oscillator, Clark-MXR CPA 1000 amplifier, $1 \mathrm{kHz}$ repetition rate at $800 \mathrm{~nm}, 100 \mathrm{fs}$ pulse width, $900 \mu \mathrm{J} /$ pulse). Briefly, the $800 \mathrm{~nm}$ output was split into two beams at 500 and $400 \mu \mathrm{J} /$ pulse, respectively. The $500 \mu \mathrm{J}$ beam was used to pump an optical parametric amplifier to generate two near-infrared pulses at about 1.5 and $1.9 \mu \mathrm{m}$, respectively. These pulses were then mixed in an $\mathrm{AgGaS}_{2}$ crystal to generate the mid-infrared probe pulse at about $5 \mu \mathrm{m}$. This probe pulse, with a bandwidth greater than $200 \mathrm{~cm}^{-1}$, was dispersed into an imaging spectrograph, where it was imaged onto a 32-element $\mathrm{HgCdTe}$ (MCT) infrared array detector. ${ }^{39}$ The amplified outputs of the 32 elements were measured for every laser shot at a $1 \mathrm{kHz}$ repetition rate. Each element of the array averaged a $5.6 \mathrm{~cm}^{-1}$ slice of the infrared spectrum so that the total spectral region covered by the array was about $180 \mathrm{~cm}^{-1}$. The other $400 \mu \mathrm{J}$ fundamental beam was attenuated with a variable neutral density filter and frequency doubled in a BBO crystal to generate $400 \mathrm{~nm}$ pulses. In all the experiments presented here, a moving film sample was pumped using $400 \mathrm{~nm}$ pulses, and the subsequent absorbance change was measured in the $1980-2200 \mathrm{~cm}^{-1}$ region. Transient kinetics traces at 32 probe wavelengths were collected simultaneously, from which transient spectra at different delay times were constructed. The diameters of the pump beam, with $1-3 \mu \mathrm{J}$ energy per pulse, and the probe beam were 400 and $300 \mu \mathrm{m}$, respectively. The instrument response function, i.e., the crosscorrelation of the pump and probe pulses, was measured in a 
thin CdS film, in which $400 \mathrm{~nm}$ excitation led to instantaneous generation of free carriers that strongly absorbed in the midinfrared region. The typical instrument response was well represented by a Gaussian function with a full-width-at-halfmaximum (fwhm) of less than 200 fs.

Nanosecond Fluorescence Spectrometer. Fluorescence lifetime measurements were carried out in a home-built fluorescence microscope. The output of Ti:Sapphire laser (Tsunami, pumped by Millennia V, Spectra-Physics) at $800 \mathrm{~nm}$ (with $\sim 50 \mathrm{fs}$ pulse duration and $80 \mathrm{MHz}$ repetition rate) was frequency doubled in a BBO crystal to generate $400 \mathrm{~nm}$ pulses. After passing a variable neutral density filter, the $400 \mathrm{~nm}$ beam is then sent to a microscope (IX70, Olympus) and focused by an oil-immersion objective lens (PlaneApo, 100X, NA $=1.4$ oil, Olympus) on a $\mathrm{ReC} 1 \mathrm{P} / \mathrm{ZrO}_{2}$ (or $\mathrm{ZrO}_{2}$ ) film coated on a glass slip. The excitation power was $0.1 \mathrm{nW}$. The emitted fluorescence was filtered by an interference band-pass filter (527-537 nm, CVI) and collected by an avalanche photodiode (APD). The APD output signal was registered by a time-correlated single photon counting (TCSPC) board (SPC600, Becker \& Hickl GmbH), from which a delay-time histogram of the detected photons was constructed. The instrument response function (IRF) was obtained by measuring light scattering of a glass slide, which has a typical fwhm of $450 \mathrm{ps}$.

Sample Preparations. $\mathrm{TiO}_{2}$ nanoparticle thin films were prepared by following a published procedure. ${ }^{22}$ Briefly, $\mathrm{TiO}_{2}$ nanoparticle colloid was prepared by a controlled hydrolysis of titanium(IV) isopropoxide in a mixture of glacial acetic acid and water at $0{ }^{\circ} \mathrm{C}$. The resulting solution was concentrated at $80{ }^{\circ} \mathrm{C}$, autoclaved at $230{ }^{\circ} \mathrm{C}$ for $12 \mathrm{~h}$, and then stirred for 4 days. A detergent (Triton X-100, Aldrich) was added to the colloid, and it was further stirred for $5 \mathrm{~h}$. The resulting suspension was spread onto polished sapphire windows and baked at $400{ }^{\circ} \mathrm{C}$ for $1 \mathrm{~h}$. $\mathrm{ZrO}_{2}$ nanoparticle thin films were prepared by using $\mathrm{ZrO}_{2}$ nanoparticle powder obtained from Degussa Corporation. Briefly, $2 \mathrm{~g}$ of $\mathrm{ZrO}_{2}$ nanoparticle powder was mixed with $4 \mathrm{~mL}$ of $\mathrm{H}_{2} \mathrm{O}$ and vigorously stirred for more than 1 week. The procedure after that, including adding a detergent, further stirring, and film preparation, was the same as that for the $\mathrm{TiO}_{2}$ films. $\mathrm{SnO}_{2}$ nanoparticle thin films were prepared by using colloidal $\mathrm{SnO}_{2}$ synthesized according to a published procedure. ${ }^{42,43}$ Briefly, $\mathrm{SnCl}_{4}$ was dissolved in $\mathrm{HCl}$ and then added dropwise into deionized water under vigorous stirring at $0{ }^{\circ} \mathrm{C}$. The $\mathrm{pH}$ of the resulting solution was adjusted to 3.5-4.0 to obtain $\mathrm{SnO}_{2}$ nanoparticle precipitate. The precipitate was washed and suspended in water by adjusting $\mathrm{pH}$ to $9.5-10$ before being dialyzed at $\mathrm{pH} 10$ to produce $\mathrm{SnO}_{2}$ colloidal solution. The $\mathrm{SnO}_{2}$ solution was refluxed and then heated in an autoclave at $150{ }^{\circ} \mathrm{C}$ for $1 \mathrm{~h}$ and at $270{ }^{\circ} \mathrm{C}$ for 16 h. The colloid was then concentrated and mixed with Triton $\mathrm{X}-100$ before being cast onto sapphire windows. After they were dried in air, the samples were baked at $400{ }^{\circ} \mathrm{C}$ for $1 \mathrm{~h}$ to produce nanoporous crystalline thin films.

ReC1P and ReC1A were prepared according to published procedures. ${ }^{38,44,45} \mathrm{TiO}_{2}$ (or $\mathrm{ZrO}_{2}$ and $\mathrm{SnO}_{2}$ ) films were immersed into dye $/ \mathrm{CH}_{3} \mathrm{OH}$ solution, resulting in dye/TiO 2 (or dye $/ \mathrm{ZrO}_{2}$ and dye $/ \mathrm{SnO}_{2}$ ) films. The sensitized films were then soaked in $\mathrm{pH}$ buffers for more than $8 \mathrm{~h}$ before use, during which small amounts of dyes desorbed from films. The typical OD of the adsorbed dye at $400 \mathrm{~nm}$ was $0.3-0.4$. Buffer solutions used in the study were $\mathrm{HCl}$ adjusted with $\mathrm{NaOH}$ for $\mathrm{pH} 0$, and $\mathrm{NH}_{4}$ $\mathrm{OH}$ adjusted with $\mathrm{HClO}_{4}$ for $\mathrm{pH}$ 2-9. All chemicals were purchased from Aldrich and used without purification. For FTIR and transient IR measurement, the sensitized films were sealed

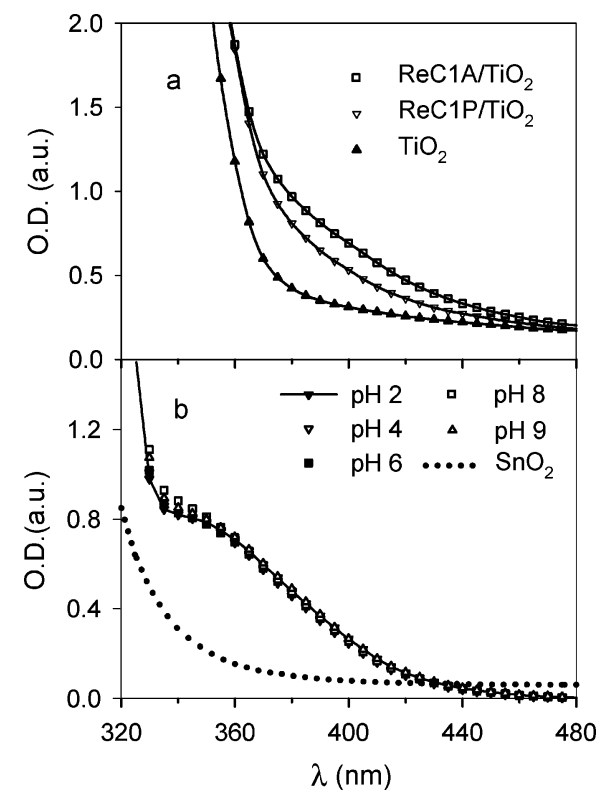

Figure 1. Absorption spectra of (a) $\mathrm{ReC} 1 \mathrm{P}$ and $\mathrm{ReC} 1 \mathrm{~A}$ sensitized $\mathrm{TiO}_{2}$ at $\mathrm{pH} 2$ and unsensitized $\mathrm{TiO}_{2}$; and (b) $\mathrm{ReC} 1 \mathrm{P}$ sensitized $\mathrm{SnO}_{2}$ at $\mathrm{pH}$ 2-9 and unsensitized $\mathrm{SnO}_{2}$ (dotted line). The $\mathrm{ReC} 1 \mathrm{P} / \mathrm{SnO}_{2}$ spectra have been corrected for $\mathrm{SnO}_{2}$ absorption to more clearly indicate the peak position of the sensitizer, which show negligible change from $\mathrm{pH} 2-9$.

in a Harrick IR cell with a $<10-\mu$ m-thick $\mathrm{pH}$ buffer layer sandwiched between a $\mathrm{CaF}_{2}$ window and the thin film (on a sapphire window). Because of limited solubility of the ReC1A and $\mathrm{ReC} 1 \mathrm{P}$ complexes in the $\mathrm{pH}$ buffer and its small volume, we estimated that less than $7 \%$ of complexes would dissolve into the buffer solution. The sample cells were scanned rapidly during measurements to prevent any long-term photoproduct build up. The integrity of the samples was checked by UV-vis (Cary 50 Bio UV-vis spectrophotometer) and FTIR spectra (Nicolet Instruments) recorded before and after the transient absorption measurement, which showed negligible degradation during the course of the measurement. All experiments were conducted at room temperature.

\section{Results}

1. pH Dependence of Photophysics. The UV-vis absorption spectra of ReC1A and $\mathrm{ReC} 1 \mathrm{P}$ on $\mathrm{TiO}_{2}$ at $\mathrm{pH} 2$ and $\mathrm{ReC} 1 \mathrm{P}$ on $\mathrm{SnO}_{2}$ at $\mathrm{pH}$ 2-9 are shown in Figure 1a and b. The spectra of $\mathrm{ReC} 1 \mathrm{~A}$ and $\mathrm{ReC} 1 \mathrm{P}$ in methanol $(\mathrm{MeOH})$ (results not shown) show a well-defined absorption band centered at $\sim 360 \mathrm{~nm}$, which has been assigned to a metal-to-ligand charge transfer (MLCT) transition. ${ }^{46}$ Similar peak positions for the MLCT band in these complexes indicate that replacing $\mathrm{COOH}$ with $\mathrm{PO}(\mathrm{OH})_{2}$ does not significantly affect the electronic structure of the bipyridine and the Re orbitals involved in the transition. The lack of sensitivity to the identity of the anchoring groups likely results from the electronically insulating $\mathrm{CH}_{2}$ spacer between the bipyridine and the anchor. As shown in Figure 1a, for these dyes adsorbed on $\mathrm{TiO}_{2}$, their absorption is clearly visible at $>380 \mathrm{~nm}$. However, the peaks of the MLCT transition are hidden by the strong $\mathrm{TiO}_{2}$ band gap absorption at $<380 \mathrm{~nm}$, which hinders a reliable determination of MLCT peak position in these films.

Because of the higher band gap transition energy in $\mathrm{SnO}_{2}$, it has less spectral overlap with the MLCT band of ReC1P and allows the determination of adsorbate peak position. As shown in Figure 1b, the MLCT band of $\mathrm{ReC} 1 \mathrm{P}$ on $\mathrm{SnO}_{2}$ shows no noticeable change from $\mathrm{pH} 2-9$. Their peak positions, centered 

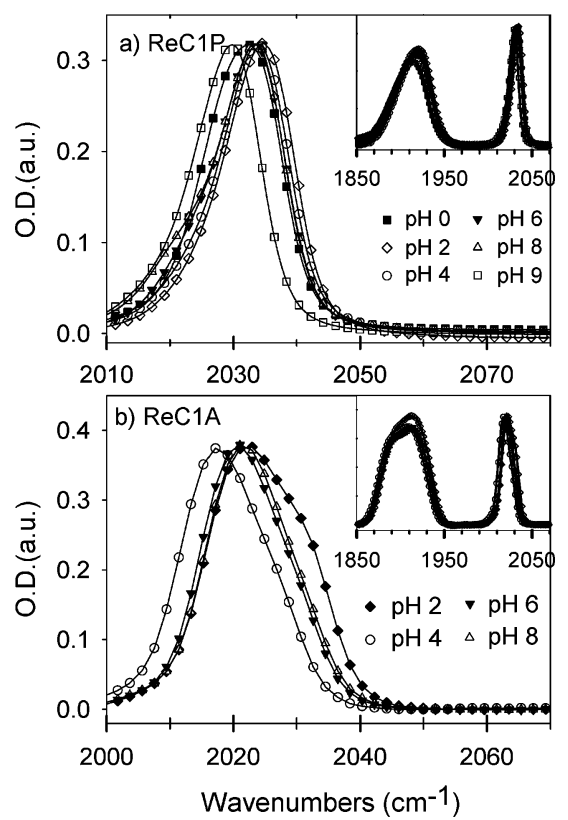

Figure 2. FTIR spectra of (a) $\mathrm{ReC} 1 \mathrm{P} / \mathrm{TiO}_{2}$ at $\mathrm{pH} 0-9$ and (b) $\mathrm{ReC} 1 \mathrm{~A} /$ $\mathrm{TiO}_{2}$ at $\mathrm{pH} 2-8$, showing the $\mathrm{a}^{\prime}(1) \mathrm{CO}$ stretching mode at $\sim 2030 \mathrm{~cm}^{-1}$. The insets show the corresponding spectra containing all three $\mathrm{CO}$ stretching modes in the $1850-2060 \mathrm{~cm}^{-1}$ region.

at $\sim 340 \mathrm{~nm}$, are similar to those in aqueous solution of $\mathrm{pH}$ 2-9 (results not shown).

The lack of $\mathrm{pH}$ dependence of the ReC1P MLCT is in contrast to the $\mathrm{pH}$-dependent MLCT band of $\mathrm{Ru}(\mathrm{dcbpy})_{2}(\mathrm{NCS})_{2}$ reported previously. ${ }^{47}$ A blue-shift of absorption maximum with increasing $\mathrm{pH}$ was observed and attributed to the deprotonation of $\mathrm{COOH}$ groups, which led to an increase in energy of the LUMO of the bipyridine ligand, shifting the MLCT transition to higher energy. Unlike the dcbpy ligand, the $\mathrm{L}_{\mathrm{A}}$ and $\mathrm{L}_{\mathrm{p}}$ ligands used in the $\mathrm{ReC} 1 \mathrm{~A}$ (or $\mathrm{ReC} 1 \mathrm{P}$ ) complexes have $\mathrm{CH}_{2}$ spacers between the $\mathrm{COOH}$ (or $\mathrm{PO}_{3} \mathrm{H}_{2}$ ) and bipyridine groups, reducing their electronic coupling. As a result, the energetics of the bipyridine ligand becomes less sensitive to the protonation state of the $\mathrm{COOH}$ or $\mathrm{PO}_{3} \mathrm{H}_{2}$ groups. For the same reason, the absorption spectra of the adsorbate show negligible shift upon adsorption to $\mathrm{SnO}_{2}$.

Figure 2 shows the FTIR spectra of $\mathrm{ReC} 1 \mathrm{P} / \mathrm{TiO}_{2}$ from $\mathrm{pH}$ 0-9 and $\mathrm{ReC} 1 \mathrm{~A} / \mathrm{TiO}_{2}$ from $\mathrm{pH} 2-8$ in the $\mathrm{CO}$ stretching mode region. The ReC1P complex shows a stronger binding than $\mathrm{ReC} 1 \mathrm{~A}$ to $\mathrm{TiO}_{2}$ and is stable over a wider $\mathrm{pH}$ range, consistent with previous experimental ${ }^{27,48-53}$ and theoretical ${ }^{54}$ observations. Under $C_{s}$ symmetry, there are three $\mathrm{CO}$ stretching modes: $\mathrm{a}^{\prime}$ (1) at $2035 \mathrm{~cm}^{-1}$ and the overlapping symmetric $\left(\mathrm{a}^{\prime}(2)\right)$ and antisymmetric a" modes at $1910 \mathrm{~cm}^{-1} .55,56$ The peak positions shift slightly with $\mathrm{pH}$ (less than $7 \mathrm{~cm}^{-1}$ ) over $\mathrm{pH} 0-9$, showing no obvious trends. The reason for the shift remains unclear. As indicated above, the change of protonation state of the dyeanchoring groups over this $\mathrm{pH}$ range has very little effect on the energetics of the MLCT transition because of the insulating $\mathrm{CH}_{2}$ spacers. Therefore, it is unlikely to be the main reason for the observed shift in $\mathrm{CO}$ stretching frequency. A more likely mechanism may be the $\mathrm{pH}$-dependent hydrogen bonding interaction between $\mathrm{CO}$ and water. Another interesting possibility is the effect of interfacial electrical field on the $\mathrm{CO}$ stretching frequency. At different $\mathrm{pH}$, the surface charge on $\mathrm{TiO}_{2}$ changes, affecting the interfacial potential and its effect on $\mathrm{CO}$ frequency. ${ }^{57}$

Before examining the effect of $\mathrm{pH}$ on interfacial electron transfer dynamics, its effect on the photophysics of these

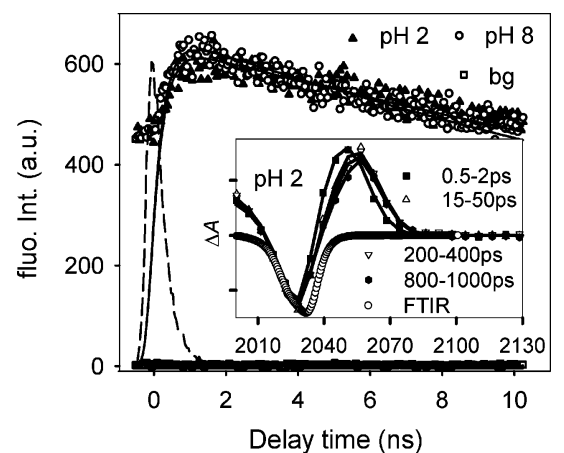

Figure 3. Fluorescence decay of $\mathrm{ReC} 1 \mathrm{P} / \mathrm{ZrO}_{2}$ in $\mathrm{pH} 2$ and 8 buffers after $400 \mathrm{~nm}$ excitation. The dashed line shows instrument response function (IRF) of the measurement. Symbols are experimental data and solid lines are fits using single-exponential decay. The unsensitized films showed negligible fluorescence (open squares). Inset shows transient absorption spectra of $\mathrm{ReC} 1 \mathrm{P} / \mathrm{ZrO}_{2}$ in $\mathrm{pH} 2$ buffer at different delay times after $400 \mathrm{~nm}$ excitation. Symbols are experimental data and lines are fits using Gaussians for both ground and excited states. Also shown for comparison is the FTIR spectrum of $\mathrm{ReC} 1 / \mathrm{ZrO}_{2}$ (open circles).

complexes needs to be investigated. To do that, we investigated the excited-state decay dynamics of $\mathrm{ReC} 1 \mathrm{P}$ on $\mathrm{ZrO}_{2}$ nanocrystalline thin films from $\mathrm{pH} 2-8$ by both transient IR absorption and fluorescence lifetime measurement. Electron injection is not expected in this system because the $\mathrm{ZrO}_{2}$ conduction band edge, at $-1.5 \mathrm{~V}$ (vs SCE) at $\mathrm{pH} 2$, is $\sim 0.8 \mathrm{~V}$ more negative than the oxidation potential of the excited state of ReC1P (at $-0.7 \mathrm{~V}$ vs SCE). ${ }^{39}$ The inset of Figure 3 shows the transient absorption spectra of a $\mathrm{ReC} 1 \mathrm{P} / \mathrm{ZrO}_{2}$ film at $\mathrm{pH} 2$ after $400 \mathrm{~nm}$ excitation. To avoid complication due to the two overlapping lowerfrequency $\mathrm{CO}$ stretching modes, the transient absorption spectra discussed herein focus on the high-frequency mode at $\sim 2035$ $\mathrm{cm}^{-1}$. The transient difference spectra consist of a bleach of the ground-state band at $2035 \mathrm{~cm}^{-1}$ and the corresponding ${ }^{3}$ MLCT excited-state absorption at $2060 \mathrm{~cm}^{-1} \cdot 39,40$ No oxidized peak at $\sim 2090 \mathrm{~cm}^{-1}$ was observed, confirming the lack of electron injection from $\mathrm{ReC} 1 \mathrm{P}$ to $\mathrm{ZrO}_{2} \cdot{ }^{39,40}$ Through all time delays, the bleach size remains constant within experimental error. The excited-state absorption also remains reasonably constant, although its peak position blue-shifts and peak width narrows with time. These dynamics have been observed previously and were attributed to vibrational cooling and changes in solvation. ${ }^{39,55,58}$ The constant bleach and excitedstate amplitude indicates negligible excited-state decay for $\mathrm{ReC} 1 \mathrm{P} / \mathrm{ZrO}_{2}$ at $\mathrm{pH} 2$ within $1 \mathrm{~ns}$. Similarly long-lived $\mathrm{ReC} 1 \mathrm{P}$ excited-state behavior is observed for $\mathrm{ReC} 1 \mathrm{P} / \mathrm{ZrO}_{2}$ in $\mathrm{pH}$ range of $0-9$.

The nanosecond excited-state decay dynamics was measured by fluorescence decay experiment. Figure 3 shows the fluorescence decay of $\mathrm{ReC} 1 \mathrm{P} / \mathrm{ZrO}_{2}$ films excited at $400 \mathrm{~nm}$ in $\mathrm{pH} 2$ and 8 buffers. Because the excited-state lifetimes of ReC1P/ $\mathrm{ZrO}_{2}$ at $\mathrm{pH} 2$ and 8 are longer than the 12 ns excitation pulse spacing, the fluorescence signal does not decay to zero before the arrival of the next excitation pulse. This leads to the nonzero signal before $t=0$. Within the signal-to-noise ratio of the measurement, fluorescence decay of $\mathrm{ReC} 1 \mathrm{P} / \mathrm{ZrO}_{2}$ at $\mathrm{pH} 2$ and 8 seem to be similar and can be fitted by single-exponential decay with lifetimes of $\sim 28 \mathrm{~ns}$ and $\sim 24 \mathrm{~ns}$ for $\mathrm{ReC} 1 \mathrm{P} / \mathrm{ZrO}_{2}$ at pH 2 and 8, respectively.

2. ReC1P on $\mathbf{T i O}_{2}$. The transient absorption difference spectra of $\mathrm{ReC} 1 \mathrm{P} / \mathrm{TiO}_{2}$ at $\mathrm{pH} 0,2$, and 9 after $400 \mathrm{~nm}$ excitation are shown in Figure 4. Similar transient spectra at $\mathrm{pH} \mathrm{4,} \mathrm{6,} \mathrm{and}$ 8 are shown in Figure S1 (in Supporting Information). The 


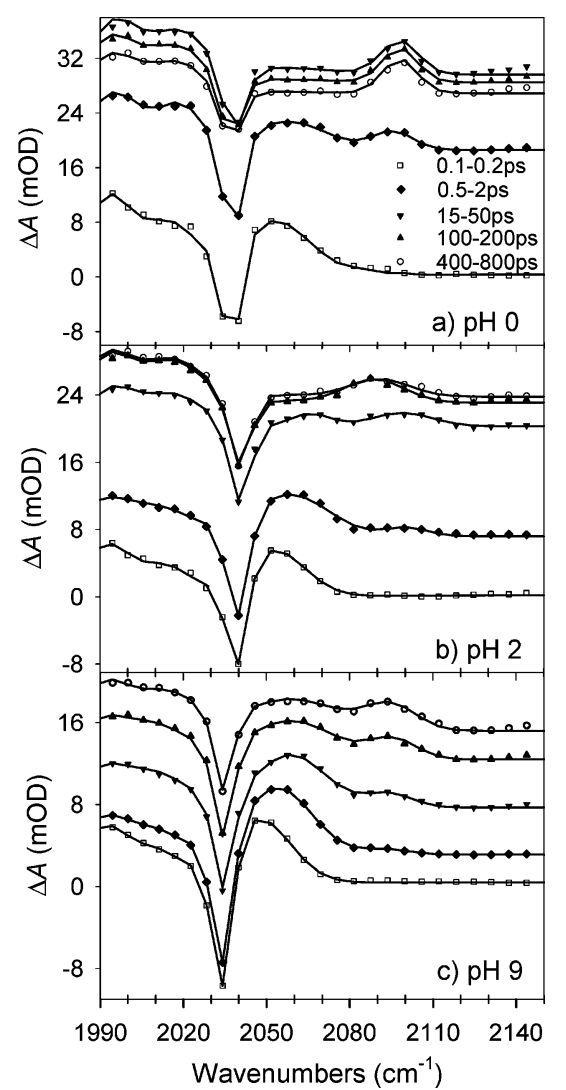

Figure 4. Transient IR absorption spectra of $\mathrm{ReC} 1 \mathrm{P} / \mathrm{TiO}_{2}$ in (a) $\mathrm{pH} 0$, (b) $\mathrm{pH} \mathrm{2,} \mathrm{and} \mathrm{(c)} \mathrm{pH} 9$ buffers after $400 \mathrm{~nm}$ excitation. The symbols are experimental data and lines are fits.

spectra at early delay times ( $<200 \mathrm{fs}$ ) resemble that of $\mathrm{ReC} 1 \mathrm{P} /$ $\mathrm{ZrO}_{2}$, consisting of a bleach of ground-state $\mathrm{CO}$ stretching band at $2035 \mathrm{~cm}^{-1}$ and the formation of the corresponding excitedstate peak at $2055 \mathrm{~cm}^{-1}$. The spectra at later delay times show two additional features: the oxidized peak at $2095 \mathrm{~cm}^{-1}$ and a broad absorption by injected electrons. The latter leads to a uniform increase of absorbance in the whole spectral range. ${ }^{38-40}$ The excited-state $\mathrm{CO}$ stretch band is blue-shifted relative to the ground state due to the reduction of electron density at the Re center upon excitation of the MLCT transition. This diminishes the backbonding from the metal center to the $\pi^{*}$ orbital of the $\mathrm{CO}$ ligand, strengthening the $\mathrm{CO}$ bond and increasing its stretching frequency. ${ }^{59-62}$ Because of mixing between the bipyridine $\pi^{*}$ orbitals and Re $\mathrm{d}$ orbitals, the oxidation of the molecule further reduces the electron density at the metal center, leading to even greater blue-shifting of the band in the oxidized dye. ${ }^{38-40}$

Electron injection from the excited state of adsorbates to $\mathrm{TiO}_{2}$ leads to a reduction of the excited-state population and a corresponding growth of absorption by the oxidized adsorbates and injected electrons. $\mathrm{pH}$-dependent temporal evolutions of the amplitude of the $\mathrm{CO}$ stretching bands in the excited and oxidized states of ReC1P as well as the electron absorption signal are clearly observed in Figure 4. Under all $\mathrm{pH}$ conditions, negligible oxidized peak amplitude was observed at $<200 \mathrm{fs,} \mathrm{indicating} \mathrm{a}$ lack of instantaneous injection component that was observed for RuN3 and derivatives on $\mathrm{TiO}_{2} \cdot{ }^{36,63-69}$ This has been attributed to the insertion of a $\mathrm{CH}_{2}$ spacer between the bipyridine and the anchoring group, which reduces its electronic coupling with $\mathrm{TiO}_{2}$, slowing down the electron injection rate. ${ }^{40}$ At $\mathrm{pH} 0$, the excited-state $\mathrm{CO}$ stretch band disappears completely by $\sim 50$ ps, with a concurrent appearance of the oxidized-state band.

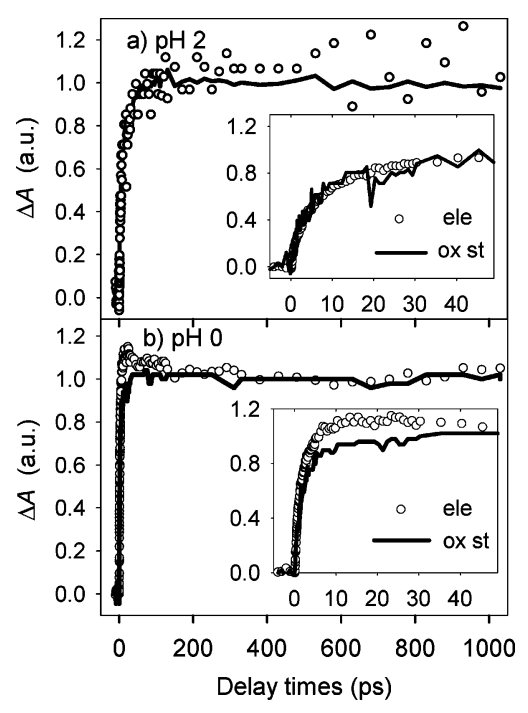

Figure 5. Comparison of the growth kinetics of the IR absorption of injected electrons (open circles) probed at $2140 \mathrm{~cm}^{-1}$ and the oxidized adsorbate $\mathrm{CO}$ stretching peak area at $\sim 2095 \mathrm{~cm}^{-1}$ (solid line) for $\mathrm{ReC} 1 \mathrm{P} / \mathrm{TiO}_{2}$ at (a) $\mathrm{pH} 2$ and (b) $\mathrm{pH} 0$. Insets show the expanded views of the comparison in $50 \mathrm{ps}$.

The peak intensity of the oxidized-state $\mathrm{CO}$ stretch band does not change after $50 \mathrm{ps}$. These results suggest that injection is completed within $50 \mathrm{ps}$, and there is negligible back ET on the $<1$ ns time scale. At $\mathrm{pH} \mathrm{2,} \mathrm{the} \mathrm{disappearance} \mathrm{of} \mathrm{the} \mathrm{excited}$ state and formation of the oxidized peak become slower, reaching completion at $\sim 200 \mathrm{ps}$. At $\mathrm{pH} 9$, the excited-state decay and the formation of oxidized peak are not completed by $800 \mathrm{ps}$, when there remains $\sim 50 \%$ excited-state population.

The electron injection kinetics can be obtained by monitoring the formation of the broad electron absorption signal of the injected electron and/or the growth of the oxidized state of the dye. The electron absorption kinetics is the product of timedependent electron population and the absorption cross-section of electrons in the conduction band. When the electron absorption cross-section does not change, the growth kinetics of the injected electron signal should agree with that of the oxidized peak. The electron absorption kinetics is determined from the absorbance change at $\sim 2140 \mathrm{~cm}^{-1}$, where the absorption is solely due to electrons in $\mathrm{TiO}_{2}$. The formation kinetics of the oxidized state is obtained by integrating the oxidized-state $\mathrm{CO}$ stretch peak area after fitting the peak using a Gaussian function. The kinetics of the electron signal and the oxidized peak for the sample at $\mathrm{pH} 2$ are compared in Figure 5a. After normalization to the same signal size at $800-1000$ ps, these two kinetics traces show good agreement, indicating that there is negligible electron cross-section decay within 1 ns. Good agreements are found in a similar kinetics comparison of the sample at $\mathrm{pH} 4-9$ (see Figure S2). Those agreements indicate that either the electron absorption or the oxidized-state peak area may be used to monitor electron injection kinetics into $\mathrm{TiO}_{2}$. However, as shown in Figure 5b, the comparison of kinetics traces for the sample at $\mathrm{pH} 0$ indicates a clear difference in the $0-200 \mathrm{ps}$ time region. This difference is attributed to the electron absorption cross-section decay in $\mathrm{TiO}_{2}$, likely indicating energy relaxation of injected electrons. Thus, only the oxidized-state kinetics is used to represent the electron injection kinetics at this $\mathrm{pH}$.

In Figure 6, we compare the electron injection kinetics for $\mathrm{ReC} 1 \mathrm{P} / \mathrm{TiO}_{2}$ films at different $\mathrm{pH}$. A small background signal of $\mathrm{TiO}_{2}$ film has been subtracted to give the displayed traces. The signal size at different $\mathrm{pH}$ has been normalized by the OD 


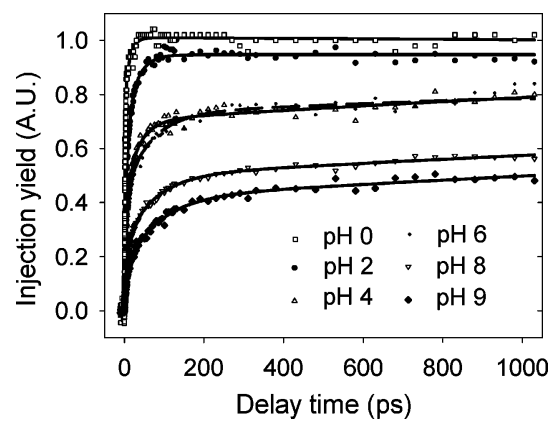

Figure 6. Comparison of the electron injection kinetics for $\mathrm{ReC} 1 \mathrm{P} /$ $\mathrm{TiO}_{2}$ films at $\mathrm{pH} 0-9$ range after $400 \mathrm{~nm}$ excitation. The symbols are experimental data and the solid curves are best three-exponential fits.

of the sample at $400 \mathrm{~nm}$ to correspond to the same number of absorbed photons. At $\mathrm{pH} 0$ and 2, the signal size reaches its maximum value by $\sim 50$ and $\sim 100 \mathrm{ps,} \mathrm{respectively,} \mathrm{suggesting}$ complete electron injection in those time scales. This is supported by the complete disappearance of the excited-state peak shown in Figure 4 . The $<10 \%$ difference in the final signal size likely reflects the error in the normalization process. The signal sizes are normalized by the number of absorbed photons, which are calculated from the average OD of the films measured in a UV-vis spectrometer. However, the transient absorption measurement may sample regions with different OD due to inhomogeneity of film thickness and adsorbate coverage. At

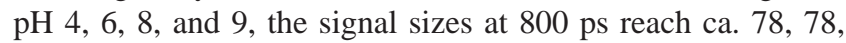
56 , and $49 \%$ of that at $\mathrm{pH} 0$, respectively. Moreover, all four traces appear to continue to grow with time, suggesting that electron injection continues beyond $1 \mathrm{~ns}$. This is consistent with the amounts of excited state that remain in these films at 800 ps, as shown in Figures 4 and $\mathrm{S} 1$.

The electron injection kinetic traces in Figure 6 are clearly nonsingle exponential and can be fit by two or three exponential rises in a multiexponential fit. To allow comparison of electron injection kinetics at different $\mathrm{pH}$, we assume that complete injection is achieved in all samples, and their final amplitudes are allowed to vary from 0.95 to 1.05 to achieve the best fit. The $\sim 10 \%$ uncertainty in signal sizes accounts for sample heterogeneity and long-term laser instability. These fits reasonably reproduce the injection dynamics. However, because there are no data points beyond $1 \mathrm{~ns}$, the parameters for the slow $(>1 \mathrm{~ns}$ ) injection component are not reliable. Therefore, average rates obtained by the amplitude-weighted average time constants, which depends sensitively on the slow components, do not provide a meaningful comparison of the relative injection rate. ${ }^{38}$ Instead, the half-rise time, $\tau_{1 / 2}$, defined as the time of $50 \%$ injection yield, is used to quantify the injection kinetics, because it can be more reliably determined in these systems. Furthermore, half-rise time can be related to characteristic times even for highly non-single-exponential processes. ${ }^{31,32,34}$ Parameters for the multiexponential fits and half-rise times for samples at different $\mathrm{pH}$ values are summarized in Table 1 . As the $\mathrm{pH}$ increases from 0 to 9 , the half-rise time for electron injection increases from $0.8 \mathrm{ps}$ to $\sim 1 \mathrm{~ns}$, slowing down by a factor of a thousand. It should be noted that the change in injection rate from $\mathrm{pH} 4-6$ is very small, as evident by the transient kinetics in Figure 6 and transient spectra in Figures 4 and S1.

3. $\mathrm{ReC1A}$ on $\mathbf{T i O}_{2}$. To test the generality of the $\mathrm{pH}$ effect, we also examined the $\mathrm{pH}$ dependence of the electron injection kinetics in $\mathrm{ReClA}$ on $\mathrm{TiO}_{2}$. As indicated earlier, the excitedstate oxidation potential of this complex is similar to $\mathrm{ReC} 1 \mathrm{P}$, but it has $\mathrm{COOH}$ instead of $\mathrm{PO}_{3} \mathrm{H}_{2}$ anchoring groups, which have different $\mathrm{p} K_{\mathrm{a}}$ values and binding strength with $\mathrm{TiO}_{2}$. The
TABLE 1: Parameters for Multiexponential Fits to and Half-rise Times of the Electron Injection Kinetics of ReC1P/ $\mathrm{TiO}_{2}$ at pH $0-9^{a}$

\begin{tabular}{lllllll}
\hline & $\mathrm{pH} 0$ & \multicolumn{1}{c}{$\mathrm{pH} 2$} & $\mathrm{pH} 4$ & \multicolumn{1}{c}{$\mathrm{pH} \mathrm{6}$} & \multicolumn{1}{c}{$\mathrm{pH} 8$} & \multicolumn{1}{c}{$\mathrm{pH}$} \\
\hline$\tau_{1} / \mathrm{ps}\left(\mathrm{A}_{1}\right)$ & $1.5(75)$ & $1.6(32)$ & $3.8(29)$ & $5.7(39)$ & $6.9(20)$ & $6.1(14)$ \\
$\tau_{2} / \mathrm{ps}\left(\mathrm{A}_{2}\right)$ & $12(25)$ & $13(58)$ & $23(40)$ & $53(33)$ & $66(27)$ & $79(27)$ \\
$\tau_{3} / \mathrm{ps}\left(\mathrm{A}_{3}\right)$ & $\mathrm{N} / \mathrm{A}$ & $126(10)$ & $2500(31)$ & $2800(28)$ & $5200(53)$ & $5700(59)$ \\
$\tau_{1 / 2}, \mathrm{ps}$ & 0.8 & 5.5 & 17 & 23 & 225 & $>1000$ \\
$\tau_{\text {rel }}$ & 0.15 & 1.0 & 3.1 & 4.2 & 41 & $>182$
\end{tabular}

${ }^{a} \tau_{n}$ and $\mathrm{A}_{n}$ (in percentage) are the lifetime and amplitude, respectively, of the $n$th exponential. Half-rise time, $\tau_{1 / 2}$, is defined as the time of $50 \%$ injection yield. $\tau_{\text {rel }}$ is the relative value of half-rise time.

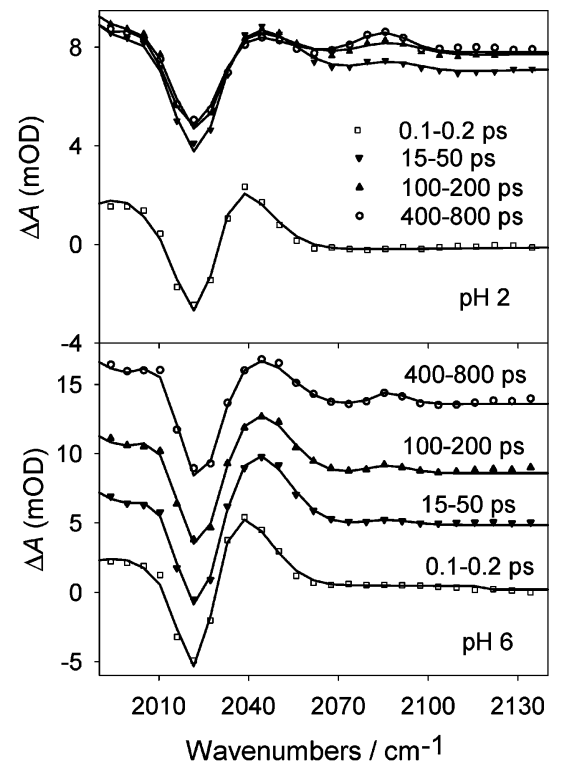

Figure 7. Transient IR spectra of $\mathrm{ReC} 1 \mathrm{~A} / \mathrm{TiO}_{2}$ at $\mathrm{pH} 2$ and 6 after $400 \mathrm{~nm}$ excitation. The symbols are experimental data and solid lines are fits.

$\mathrm{p} K_{\mathrm{a}}$ values for the protonation of first and second protons for the $-\mathrm{COO}$ group of the dcbpy ligand were found to be 3 and $1.5 .{ }^{47} \mathrm{p} K_{\mathrm{a}}$ values for $\mathrm{Ru}(\mathrm{bpy})_{2}\left(\mathrm{bpy}-\mathrm{R}-\mathrm{PO}_{3} \mathrm{H}_{2}\right)^{2+}[\mathrm{R}=$ phenyl $]$ were reported to be 6.3 and $<2 .^{70,71}$ If the 1000 -fold decrease in injection rate observed in $\mathrm{ReC} 1 \mathrm{P} / \mathrm{TiO}_{2}$ is dominated by a $\mathrm{pH}$-dependent conduction band edge shift, then a similar trend should be observed in $\mathrm{ReC} 1 \mathrm{~A}$. However, if the injection rate change results from a $\mathrm{pH}$-dependent binding of adsorbates, then a different trend may be observed. The transient absorption difference spectra of $\mathrm{ReC} 1 \mathrm{~A} / \mathrm{TiO}_{2}$ at $\mathrm{pH} 2$ and 6 after $400 \mathrm{~nm}$ excitation are shown in Figure 7. Similar transient spectra at pH 4 and 8 are shown in Figure S3. The CO stretching mode of the complex in ground, excited states, and oxidized form are similar to that of $\mathrm{ReC} 1 \mathrm{P} / \mathrm{TiO}_{2}$ system and have been previously assigned. ${ }^{38-40}$ Again, the transient spectra indicate that, with increasing $\mathrm{pH}$, the formation of oxidized peak and the decay of excited state become slower. The injection rates appear to be significantly slower than those in $\mathrm{ReC} 1 \mathrm{P} / \mathrm{TiO}_{2}$. At $\mathrm{pH} 2$, there remains $\sim 20 \%$ excited-state population at $800 \mathrm{ps}$ for ReC1A, whereas for the corresponding ReC1P complex, the injection is completed by 200 ps.

Electron injection kinetics traces are constructed from the oxidized peak formation and electron absorption signal at $\sim 2120$ $\mathrm{cm}^{-1}$ and compared in Figure S4. Good agreements between these traces were found for all $\mathrm{pH}$ values. Only the injection kinetics traces obtained from the electron absorption signal are shown in Figure 8, in which the electron injection kinetics of $\mathrm{ReC} 1 \mathrm{~A}$ on $\mathrm{TiO}_{2}$ films at $\mathrm{pH} 2-8$ are compared. They can be 


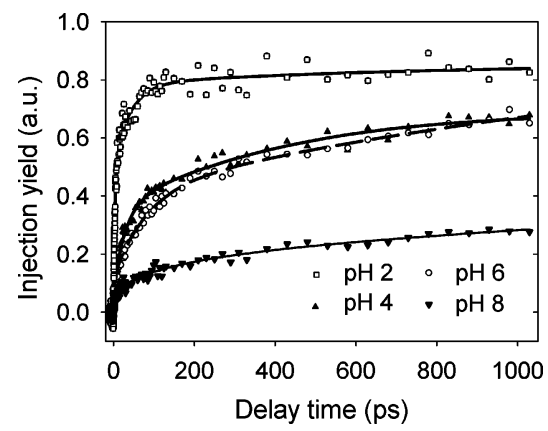

Figure 8. Comparison of electron injection kinetics of $\mathrm{ReC} 1 \mathrm{~A}$ on $\mathrm{TiO}_{2}$ films at $\mathrm{pH} 2-8$ probed at $2120 \mathrm{~cm}^{-1}$ after $400 \mathrm{~nm}$ excitation. The symbols are experimental data and the solid and dashed curves are three-exponential fits.

TABLE 2: Parameters for Three-Exponential Fits to and Half-rise Times of the Electron Injection Kinetics of ReC1A/ $\mathrm{TiO}_{2}$ at pH 2-8

\begin{tabular}{lllll}
\hline & \multicolumn{1}{c}{$\mathrm{pH} 2$} & \multicolumn{1}{c}{$\mathrm{pH} 4$} & \multicolumn{1}{c}{$\mathrm{pH} \mathrm{6}$} & \multicolumn{1}{c}{$\mathrm{pH} 8$} \\
\hline$\tau_{1} / \mathrm{ps}\left(\mathrm{A}_{1}\right)$ & $3.5(44)$ & $7.7(17)$ & $3.2(11)$ & $12.5(7)$ \\
$\tau_{2} / \mathrm{ps}\left(\mathrm{A}_{2}\right)$ & $39(33)$ & $68(29)$ & $95(35)$ & $382(20)$ \\
$\tau_{3} / \mathrm{ps}\left(\mathrm{A}_{3}\right)$ & $2570(23)$ & $1825(54)$ & $1968(54)$ & $4500(72)$ \\
$\tau_{1 / 2}(\mathrm{ps})$ & 7.9 & 210 & 290 & $>1 \mathrm{~ns}$ \\
$\tau_{\text {rel }}$ & 1 & 27 & 37 & $>250$
\end{tabular}

${ }^{a} \tau_{n}$ and $\mathrm{A}_{n}$ (in percentage) are the lifetime and amplitude, respectively, of the $n$th exponential. Half-rise time, $\tau_{1 / 2}$, is defined as the time of $50 \%$ injection yield. $\tau_{\text {rel }}$ is the relative value of half-rise time

well fit by three-exponential rise functions and the fitting parameters are summarized in Table 2. Again, because the slow component is much slower than the 1 ns observation window, the amplitude-weighted average lifetime is not a reliable way to characterize the injection rate. Instead, the half-rise times $\left(\tau_{1 / 2}\right)$ of the injection kinetics are determined and used to compare the relative injection rates. Similar to that of $\mathrm{ReC} 1 \mathrm{P} / \mathrm{TiO}_{2}$, injection rate slows down from $\mathrm{pH} 2-8$ by a factor of $>250$. It is worth noting that the injection kinetics of $\mathrm{pH} 4$ and 6 are again similar.

4. ReC1P on $\mathrm{SnO}_{2}$. For both $\mathrm{ReC} 1 \mathrm{P}$ and $\mathrm{ReClA}$ on $\mathrm{TiO}_{2}$, the electron injection rates are sensitive to the $\mathrm{pH}$ of the solution. As we will discuss later, if the dependence is dominated by the $\mathrm{pH}$-dependent conduction band edge, this sensitivity likely arises from the proximity of the excited-state oxidation potential with the conduction band edge, a region with exponential dependence of density of states on energy. For an adsorbate with the excitedstate oxidation potential that is significantly above the bandedge, the injection rate is expected to vary more slowly with the relative energetics. Unfortunately, because of a limited range of sample stability, we cannot extend the above measurements to lower $\mathrm{pH}$ values. Instead, we choose to examine the $\mathrm{pH}$ dependence of the injection kinetics of $\mathrm{ReC} 1 \mathrm{P}$ on $\mathrm{SnO}_{2}$. The conduction band edge $\mathrm{SnO}_{2}$ is about $0.5 \mathrm{~V}$ lower than $\mathrm{TiO}_{2},{ }^{3}$ allowing the study of $\mathrm{pH}$ dependence for accepting states further above the band edge.

Figure 9 shows electron injection kinetics of $\mathrm{ReC} 1 \mathrm{P} / \mathrm{SnO}_{2}$ at pH 2-9 probed at $2150 \mathrm{~cm}^{-1}$ after $400 \mathrm{~nm}$ excitation. Because of the much stronger electron absorption cross section in $\mathrm{SnO}_{2}$, obtaining reliable transient absorption spectra of the adsorbate is difficult. We have previously shown that, for $\mathrm{ReC} 1 \mathrm{~A}^{38-40}$ and $\mathrm{ReC}_{1} \mathrm{P}^{41}$ on $\mathrm{SnO}_{2}$, the kinetic traces constructed from the oxidized peak and injected electron absorption are identical, suggesting that monitoring the electron absorption signal is sufficient in this system. The kinetic traces in Figure 9 have been normalized to correspond to the same number of absorbed

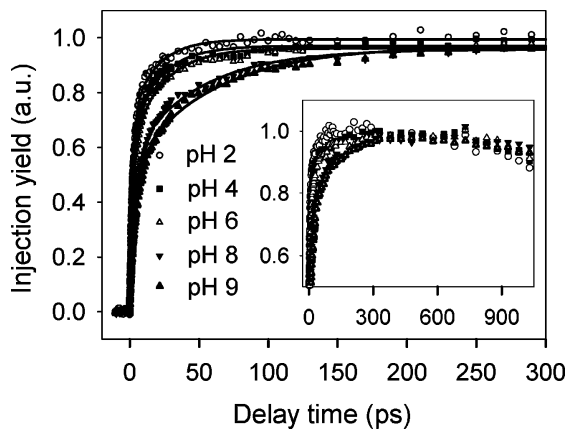

Figure 9. Comparison of electron injection kinetics of $\mathrm{ReC} 1 \mathrm{P} / \mathrm{SnO}_{2}$ probed at $2150 \mathrm{~cm}^{-1}$ at different $\mathrm{pH}$. The inset shows the injection kinetics within $1 \mathrm{~ns}$, indicating some signal decay $(<10 \%)$ due to recombination. The symbols are experimental data and the solid lines are fits using two exponential rise.

TABLE 3: Parameters for Biexponential Fits to and Half-rise Times of the Electron Injection Kinetics of ReC1P/ $\mathrm{SnO}_{2}$ at $\mathrm{pH}_{2}-\mathrm{9}^{a}$

\begin{tabular}{lccccc}
\hline & $\mathrm{pH} 2$ & $\mathrm{pH} 4$ & $\mathrm{pH} \mathrm{6}$ & $\mathrm{pH} 8$ & $\mathrm{pH} 9$ \\
\hline$\tau_{1},\left(\mathrm{~A}_{1}\right)$ & $2.0(66)$ & $2.3(64)$ & $2.6(58)$ & $4.1(59)$ & $5.3(59)$ \\
$\tau_{2},\left(\mathrm{~A}_{2}\right)$ & $18(34)$ & $21(36)$ & $23(42)$ & $49(41)$ & $59(41)$ \\
$\tau_{\text {ave }}$ & 7.5 & 9.0 & 11.2 & 22.5 & 27.3 \\
$\tau_{\text {ave-rel }}$ & 1 & 1.2 & 1.5 & 3.0 & 3.7 \\
$\tau_{1 / 2}, \mathrm{ps}$ & 2.3 & 2.8 & 3.6 & 7.0 & 9.5 \\
$\tau_{\text {rel }}$ & 1 & 1.2 & 1.6 & 3.0 & 4.1
\end{tabular}

${ }^{a} \tau_{n}$ and $\mathrm{A}_{n}$ (in percentage) are the lifetime and amplitude, respectively, of the $n$th exponential. $\tau_{\text {ave }}$ is amplitude-weighted average time constant as defined in eq 2. $\tau_{\text {ave-rel }}$ is the relative average time. Halfrise time, $\tau_{1 / 2}$, is defined as the time of $50 \%$ injection yield. $\tau_{\text {rel }}$ is the relative value of half-rise time.

photons. Injection appears to have completed within 300 ps for all $\mathrm{pH}$, and they reach the same final value of injection yield at about 300 ps. This is consistent with the transient spectra observed previously for $\mathrm{ReC} 1 \mathrm{P}$ on $\mathrm{SnO}_{2}$ under ambient condition (exposed to air), in which a complete decay of the excitedstate peak was observed within 300 ps. ${ }^{41}$ This earlier study also showed that there was a noticeable decay of the electron signal at longer delay times due to back electron transfer. ${ }^{41}$ Similar decays were observed in the current system as shown in the inset of Figure 9. Because the back ET rate is much slower than the injection rate, these two steps are reasonably well separated. Therefore, the injection kinetics in the $<300$ ps region were fit by multiexponential rise. The time constants and amplitude for best biexponential fits are shown in Table 3 . Because electron injection is completed within $300 \mathrm{ps}$, all injection components are well determined. The amplitudeweighted average time constants are calculated from the biexponential fit:

$$
\tau_{\text {ave }}=\frac{A_{1} \tau_{1}+A_{2} \tau_{2}}{A_{1}+A_{2}}
$$

The average injection times and their relative value in different $\mathrm{pH}$ are listed in Table 3. It is interesting to note that, in this case, the relative amplitude-weighted average injection times and half-rise times $\left(\tau_{1 / 2}\right)$ show good agreement with each other. In this system, the injection rate also decreases from $\mathrm{pH}$ $2-9$, but overall change is only a factor of 4 instead of $\sim 182$ observed for the same dye on $\mathrm{TiO}_{2}$.

\section{Discussion}

pH Dependence of ET Rate. To understand the observed $\mathrm{pH}$ dependence, we compare the experimental results with 
predictions based on Marcus' theory of interfacial ET. ${ }^{8-11}$ In the nonadiabatic limit, the total electron injection rate from molecular excited state into the nanoparticle can be expressed as the sum of ET rates to all possible accepting states in the semiconductor. ${ }^{8-11}$ For an adsorbate excited state with redox potential of $E\left(\mathrm{~S}^{+} / \mathrm{S}^{*}\right)$ or $E_{\mathrm{OX}}$, the driving force for injection to a semiconductor $\mathbf{k}$ state at $E$ above band edge $\left(E_{\mathrm{CB}}\right)$ is $\Delta G(E)$ $=\left(E_{\mathrm{CB}}+E\right)-E\left(\mathrm{~S}^{+} / \mathrm{S}^{*}\right)$. The total injection rate can be expressed as:

$$
\begin{array}{r}
k_{\mathrm{ET}}=\frac{2 \pi}{\hbar} \int_{-\infty}^{\infty} \mathrm{d} E \rho(E)\left(1-f\left(E, E_{\mathrm{F}}\right)\right)|\bar{H}(E)|^{2} \frac{1}{\sqrt{4 \pi \lambda k_{\mathrm{B}} T}} \times \\
\exp \left[-\frac{\left(\lambda+\Delta G_{0}+E\right)^{2}}{4 \lambda k_{\mathrm{B}} T}\right]
\end{array}
$$

In eq $3, \Delta G_{0}=E_{\mathrm{CB}}-E\left(\mathrm{~S}^{+} / \mathrm{S}^{*}\right) ; \rho(E)$ is the density of states (per unit energy) at energy $E$ relative the conduction band edge, which can include both bulk, surface, and defect states; $H(E)$ is the average electronic coupling between the adsorbate excited state and all semiconductor states at energy $E$; and $\lambda$ is the total reorganization energy. The Fermi occupancy factor, $f\left(E, E_{\mathrm{F}}\right)$, which ensures that electron injection occurs only to unfilled product states, can be assumed to be 0 for conduction band states in this case.

For $\mathrm{TiO}_{2}$ and $\mathrm{SnO}_{2}$, the conduction band states are composed of $\mathrm{Ti}^{4+} 3 \mathrm{~d}$ and $\mathrm{Sn}^{4+} 5 \mathrm{~s}$ and $5 \mathrm{p}$ orbitals, respectively. ${ }^{72}$ Both $-\mathrm{PO}_{3} \mathrm{H}_{2}$ and $-\mathrm{COOH}$ anchoring groups are believed to bind with metal ions. ${ }^{73}$ It is assumed that electronic interaction of adsorbate with the nanoparticle only involves the first metal ions that are in direct contact with the anchoring group with a total strength of $H_{0}$. The electronic coupling of the adsorbate with a $\mathbf{k}$ state in the semiconductor depends on the nature of the state and adsorption site, ${ }^{74,75}$ a detailed description of which awaits future computational studies. ${ }^{11}$ To give a general and qualitative description, it is assumed that the average electronic coupling is independent of the energy of $\mathbf{k}$ states and the density of electron-accepting states is given by the total density of states. We define $\rho_{0}(E)$ as the density of states per unit energy within the average volume of a metal center, $V_{0}$, which is calculated by dividing the unit cell volume by the number of metal centers in it. (Average volume of a metal center instead of volume of a unit cell is used for comparison because the latter contains different number of metal centers in anatase and rutile crystals. ${ }^{13}$ ) In a nanoparticle with $N$ metal centers, the total density of states should scale with $N$, while the square of electronic coupling strength per state should depend inversely on $N:^{76}$

$$
\begin{gathered}
\rho(E) \mathrm{d} E=N^{*} \rho_{0}(E) \mathrm{d} E \\
|H(E)|^{2}=\frac{1}{N}\left|H_{0}\right|^{2}
\end{gathered}
$$

Within these assumptions, the total injection rate is independent of particle size and can then be expressed as:

$$
\begin{aligned}
& k_{\mathrm{ET}}=\frac{2 \pi}{\hbar} \int_{-\infty}^{\infty} \mathrm{d} E \rho_{0}(E)\left|H_{0}\right|^{2} \frac{1}{\sqrt{4 \pi \lambda k_{\mathrm{B}} T}} \times \\
& \exp \left[-\frac{\left(\lambda+\Delta G_{0}+E\right)^{2}}{4 \lambda k_{\mathrm{B}} T}\right]
\end{aligned}
$$

For most metal oxide nanocrystalline thin films, their density of states shows an exponential tail below the band edge. ${ }^{31,32,77,78}$ To model this defect density of states, we assume that their

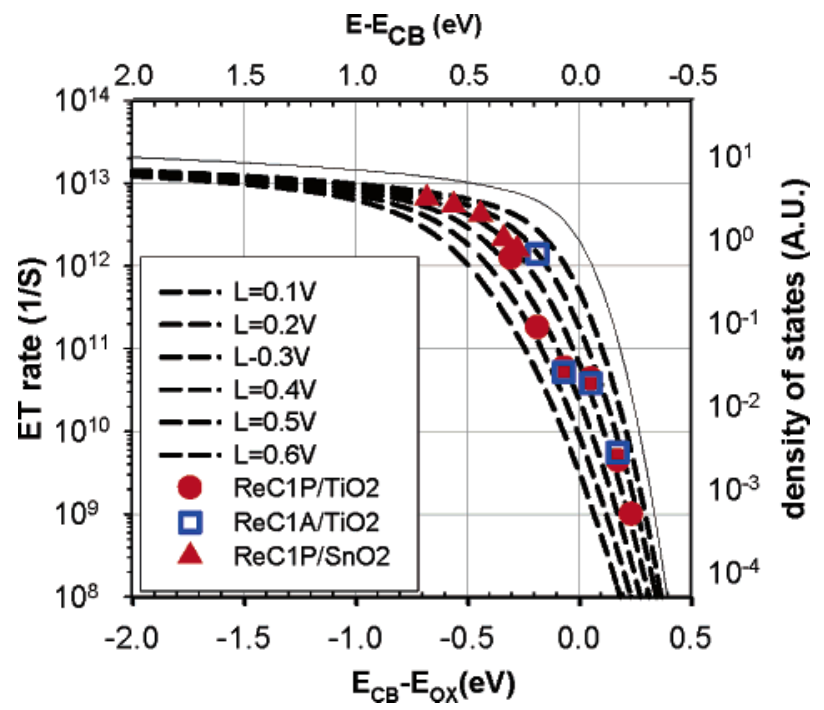

Figure 10. Comparison of calculated electron injection rate (dashed line) as a function of $E_{\mathrm{CB}}-E\left(\mathrm{~S}^{*} / \mathrm{S}^{+}\right)$and measured electron injection rate in $\mathrm{ReC} 1 \mathrm{~A}$ and $\mathrm{ReC} 1 \mathrm{P}$ on $\mathrm{TiO}_{2}$ and $\mathrm{ReC} 1 \mathrm{P}$ on $\mathrm{SnO}_{2}$ at different $\mathrm{pH}$. The calculated rates were obtained using eq 5 for a range of reorganization energies $(0.1-0.6 \mathrm{eV})$ for anatase $\mathrm{TiO}_{2}$ with $H_{0}=100$ $\mathrm{cm}^{-1}$, which leads to the best agreement with the measured values for $\mathrm{ReC} 1 \mathrm{P} / \mathrm{TiO}_{2}$. The measured injection rates for $\mathrm{ReC} 1 \mathrm{P} / \mathrm{SnO}_{2}$ and $\mathrm{ReC} 1 \mathrm{~A} /$ $\mathrm{TiO}_{2}$ have been multiplied by a factor of 15 and 11, respectively, to allow comparison on the same curves. A plot of the density of states in the semiconductor (right axis) as a function of energy relative to the band edge (top axis) is shown by the thin solid curve. It was calculated using eq 7 for $\Delta=100 \mathrm{meV}$.

presence perturbs the energy of a perfect crystal and the energy perturbation obeys a Gaussian distribution function. A similar approach is often used to model amorphous semiconductors. ${ }^{79}$ We assume that the density of states near the conduction band edge in a perfect oxide crystal can be described by:

$$
\rho_{0 C}(E) \mathrm{d} E=V_{0} \frac{\left(2 m^{*}\right)^{3 / 2}}{2 \pi^{2} \hbar^{3}} \sqrt{E} \mathrm{~d} E
$$

where $\mathrm{m}^{*}$ is the effective mass of electrons in the conduction band. The density of states in nanocrystalline films can be modeled as:

$$
\rho_{0}(E)=\int_{0}^{\infty} \rho_{0 c}\left(E^{\prime}\right) \frac{1}{\Delta \sqrt{2 \pi}} e^{-\left(E-E^{\prime}\right)^{2} / 2 \Delta^{2}} \mathrm{~d} E^{\prime}
$$

Inclusion of defects leads to negligible change of state density above the band edge, but creates substantial density of states below the band edge that decayed roughly exponentially $\left(\mathrm{g}(E) \sim \mathrm{e}^{-\mathrm{a}(E \mathrm{c}-E)}\right)$. The decay rate decreases (extending further below the band edge) with increase in the width of the Gaussian distribution. Shown in Figure 10 is a curve calculated with the width of the Gaussian distribution function, $\Delta$, of $100 \mathrm{meV}$. This width was chosen such that the calculated ET rate below the band edge agrees with the measured data, as will be discussed later. The corresponding density of states decay roughly exponentially below the band edge with an decay constant of $a=15(\mathrm{eV})^{-1}$, similar to those used to model defect state densities of $\mathrm{TiO}_{2}$ nanocrystalline electrodes in other studies. ${ }^{31,32,77,78}$

This equation predicts that injection rate depends sensitively on the electronic coupling strength, the density of states per unit volume in the solid, and the relative position of adsorbate potential and band edge. Shown in Figure 10 are the calculated injection rate, $k_{\mathrm{ET}}$ as a function of $E_{\mathrm{CB}}-E\left(\mathrm{~S}^{+} / \mathrm{S}^{*}\right)$. The injection 
rate increases when the adsorbate excited-state oxidation potential lies further above the conduction band edge. The variation is slow high above the band edge, but is nearly exponential near the band edge, reflecting the energy-dependent density of states in semiconductor, which is also shown by the thin solid line. Similar trends are observed for reorganization energy from 0.1 to $0.6 \mathrm{eV}$, although for a given $E_{\mathrm{CB}}-E_{\mathrm{OX}}$ value, the injection rate decreases with reorganization energy when $E_{\mathrm{OX}}$ is near $E_{\mathrm{CB}}$. The dependence on the reorganization energy becomes negligible when $E_{\mathrm{OX}}$ is over $1 \mathrm{~V}$ above the band edge.

To compare with the experimental data, the total coupling strength $H_{0}$ is varied until the calculated rates are in best agreement with the measured values. Other parameters are determined by the nature of the semiconductor; we have used $V_{0}=34.9$ and $35.8 \AA^{313,76}$ and $m^{*}=10$ and $0.3 m_{0}{ }^{80,81}\left(m_{0}\right.$ is the mass of free electron) for anatase $\mathrm{TiO}_{2}$ and rutile $\mathrm{SnO}_{2}$ respectively. The slope of the density of states below the band edge, which determines how ET rate varies with energy in this region, is determined largely by the width of the Gaussian distribution function used in eq 7. A best fit of the data for $\mathrm{TiO}_{2}$ leads to a width of $100 \mathrm{meV}$. The measured injection rates are plotted against the values of $E_{\mathrm{CB}}-E\left(\mathrm{~S}^{+} / \mathrm{S}^{*}\right)$, with the $\mathrm{pH}$ dependent $E_{\mathrm{CB}}$ position given by eq 1 and $E\left(\mathrm{~S}^{+} / \mathrm{S}^{*}\right)=-0.7 \mathrm{~V}$ (vs SCE). ${ }^{36,40}$ For $\mathrm{ReC} 1 \mathrm{P} / \mathrm{TiO}_{2}$, the best agreement with the measured value is achieved with a $H_{0}$ value of about $\sim 100 \mathrm{~cm}^{-1}$. To compare the $\mathrm{pH}$ dependence of $\mathrm{ReC} 1 \mathrm{~A} / \mathrm{TiO}_{2}$ and $\mathrm{ReC} 1 \mathrm{P} /$ $\mathrm{SnO}_{2}$ on the same calculated curves, the measured injection rates in these systems were multiplied by a factor of 11 and 15 , respectively. These scaling factors, which reflect the difference of injection rates for the same sensitizer on different metal oxides and between different sensitizers on the same substrate, will be discussed later.

As shown in Figure 10, the electron injection rate is strongly $\mathrm{pH}$ dependent for ReC1P and $\mathrm{ReC} 1 \mathrm{~A}$ on $\mathrm{TiO}_{2}$, but weakly $\mathrm{pH}$ dependent for ReC1P on $\mathrm{SnO}_{2}$. For $\mathrm{ReC} 1 \mathrm{P} / \mathrm{TiO}_{2}$ and $\mathrm{ReC} 1 \mathrm{~A} /$ $\mathrm{TiO}_{2}$, increasing $\mathrm{pH}$ from 0 to 9 changes the $E_{\mathrm{CB}}-E_{\mathrm{OX}}$ value from -0.3 to $+0.23 \mathrm{~V}$, suggesting that accepting states are near and below the band edge. ET in these systems falls in a range in which electron-accepting state density changes sensitively on the $\mathrm{pH}$-dependent band edge. For $\mathrm{ReC} 1 \mathrm{P}$ on $\mathrm{SnO}_{2}$, because of the $\sim 0.5 \mathrm{~V}$ lower conduction band edge, the $E_{\mathrm{CB}}-E_{\mathrm{OX}}$ value varies from $-0.8 \mathrm{~V}$ at $\mathrm{pH} 0$ to $-0.37 \mathrm{~V}$ at $\mathrm{pH} 9$, indicating ET to states above the band edge. In this case, energetic change has a relatively small effect on electron-accepting state density and ET rate. It appears that in all three systems, covering a change of $E_{\mathrm{CB}}-E_{\mathrm{OX}}$ value from -0.8 to $+0.23 \mathrm{~V}$, the effect of $\mathrm{pH}$ on electron injection rate can be qualitatively understood by considering the effect of $\mathrm{pH}$ on band edge position and the corresponding electron-accepting state density in the semiconductors.

Although the above comparison is suggestive of the dominant effect of $\mathrm{pH}$-dependent band edge on injection rate, other factors should also be considered. It is unclear how electronic coupling strength varies with $\mathrm{pH}$. Binding constants of these complexes decrease when $\mathrm{pH}$ is below $\sim 2$ or above $\sim 9$ in both $\mathrm{TiO}_{2}$ and $\mathrm{SnO}_{2}$, indicating a nonmonotonic dependence of binding constant on $\mathrm{pH}$. The dramatically different $\mathrm{pH}$ effect on ET rate on $\mathrm{SnO}_{2}$ and $\mathrm{TiO}_{2}$ suggests that variation of coupling strength with $\mathrm{pH}$ is not sufficient to account for the 1000 -fold change of injection rate observe on $\mathrm{TiO}_{2}$.

In addition to band edge, $\mathrm{pH}$-dependent surface charges can also affect the adsorbate redox potential, as discussed above. ${ }^{22,57}$ The $\mathrm{pH}$ dependences of the ground-state oxidation potentials

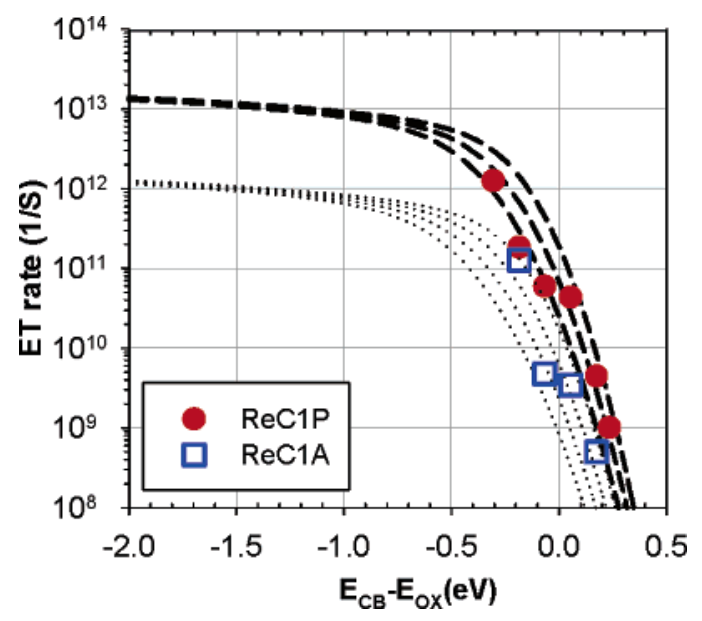

Figure 11. Comparison of calculated electron injection rate (dashed line) as a function of $E_{\mathrm{CB}}-E\left(\mathrm{~S}^{*} / \mathrm{S}^{+}\right)$and measured electron injection rate in $\mathrm{ReC} 1 \mathrm{~A}$ and $\mathrm{ReC} 1 \mathrm{P}$ on $\mathrm{TiO}_{2}$ at different $\mathrm{pH}$. The rates are calculated using eq 5 for a range of reorganization energies $(0.1-0.4$ $\mathrm{V})$. The best fits to the measured values for ReC1P and $\mathrm{ReC} 1 \mathrm{~A}$ were obtained with $H_{0}=100$ and $30 \mathrm{~cm}^{-1}$, respectively.

$\mathrm{ReC} 1 \mathrm{P}$ and $\mathrm{ReC} 1 \mathrm{~A}$ (from which the excited-state potentials can be calculated) are not easily determined, especially when surface attached, because of rapid (on an electrochemical time scale) decomposition of the oxidized species, inherently unstable "19electron" organometallic species. A reasonable guess, on the basis of measurements with related compounds, would be -15 to $-20 \mathrm{mV}$ per $\mathrm{pH}$ unit for $\mathrm{TiO}_{2}$. This would result in a somewhat smaller change of $E_{\mathrm{CB}}-E_{\mathrm{OX}}(40-45 \mathrm{mV} / \mathrm{pH})$ and a weaker $\mathrm{pH}$ dependence for the ET rate. For $\mathrm{SnO}_{2}$, the dependence of the $\zeta$ potential on $\mathrm{pH}$ is minimal between 9 and about 4 , but the potential shifts in the positive direction as the $\mathrm{pH}$ moves below $4 .^{71}$ Consequently, the redox potentials for dyes attached to tin oxide should be less sensitive to $\mathrm{pH}$ than those on $\mathrm{TiO}_{2}$, except at the lowest pHs. It appears that the primary effect of $\mathrm{pH}$ upon the injection kinetics comes from the shift of band edge with $\mathrm{pH}$.

The observed $\mathrm{pH}$ dependence of electron injection rate of $\mathrm{ReC} 1 \mathrm{~A}$ and $\mathrm{ReC} 1 \mathrm{P}$ on $\mathrm{TiO}_{2}$ is consistent with a previous report for RuN3 and $\mathrm{Ru}(\mathrm{dcbpy})_{3}$ on $\mathrm{TiO}_{2}{ }^{36}$ In these systems, the injection dynamics were biphasic with a $<100$ fs fast component and slower components. Increasing $\mathrm{pH}$ from 2 to 8 led to a decrease of the amplitude of the fast component and the rate the slow components. Similar $\mathrm{pH}$ and cation dependence of injection dynamics have also been reported by other groups. ${ }^{35,82,83}$ Electron injection rate in $\mathrm{RuN} 3 / \mathrm{TiO}_{2}$ was shown to increase in solution with higher $\mathrm{Li}^{+}$cation concentration due to $\mathrm{Li}^{+}$ dependent conduction band edge position. ${ }^{83}$ It was also observed that an increase of cation and proton concentration reduced luminescence quantum yield of $\mathrm{Ru}$ dye-sensitized $\mathrm{TiO}_{2}$ films, ${ }^{35,82}$ suggesting faster injection rates under those conditions.

Anchoring Group Dependence. As shown in Tables 1 and 2, the injection rates to $\mathrm{TiO}_{2}$ from $\mathrm{ReC} 1 \mathrm{P}$ are faster than those from $\mathrm{ReC} 1 \mathrm{~A}$ at the same $\mathrm{pH}$. For these systems at the same $\mathrm{pH}$, the values of $E_{\mathrm{CB}}-E_{\mathrm{OX}}$ and $\lambda$ are similar and the rate difference can be attributed to variation in electronic coupling strength. The best fit of these rates using eq 5 leads to $H_{0}$ values of 100 and $30 \mathrm{~cm}^{-1}$ for ReC1P and ReC1, respectively (Figure 11). This result indicates that anchoring groups can have a significant effect on the interfacial ET rate. It should be noted that a large effect of anchor group on molecular conductance was pointed out in a previous theoretical study. ${ }^{84}$ 


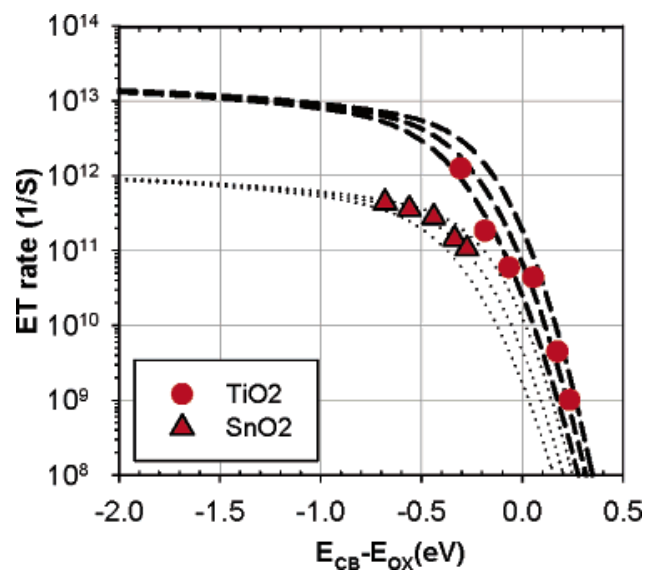

Figure 12. Comparison of calculated electron injection rate (dashed line) as a function of $E_{\mathrm{CB}}-E\left(\mathrm{~S}^{*} / \mathrm{S}^{+}\right)$and measured electron injection rate in $\mathrm{ReC} 1 \mathrm{P}$ on $\mathrm{TiO}_{2}$ and $\mathrm{SnO}_{2}$ at different $\mathrm{pH}$. The rates are calculated using eq 5 for a range of reorganization energies $(0.1-0.4 \mathrm{~V})$. The best fits to the measured values for $\mathrm{TiO}_{2}$ and $\mathrm{SnO}_{2}$ were obtained with $H_{0}=100$ and $350 \mathrm{~cm}^{-1}$, respectively.

These anchoring groups differ in both the binding strength to surface ${ }^{27,48-53}$ and electronic structure. ${ }^{52,54}$ Stronger binding of phosphonate to $\mathrm{TiO}_{2}$ than the carboxylate anchoring group has been observed in experiments ${ }^{27,48-53}$ and confirmed in computational modeling. ${ }^{54}$ A recent periodic hybrid HF-DFT study of $\mathrm{HPO}_{3} \mathrm{H}_{2}$ and $\mathrm{HCOOH}$ on anatase $\mathrm{TiO}_{2}$ (101) surface has found the binding energy in the former to be $\sim 20 \mathrm{kcal} / \mathrm{mol}$ larger. ${ }^{54}$ An atomic-level understanding of how these differences in the anchoring group affect electronic coupling awaits more detailed computational studies.

Semiconductor Dependence. As shown in Tables 1 and 3 and Figure 12, the injection rate from $\mathrm{ReC} 1 \mathrm{P}$ to $\mathrm{SnO}_{2}$ is faster than that to $\mathrm{TiO}_{2}$ at the same $\mathrm{pH}$. Their difference changes from a factor of $\sim 2$ at $\mathrm{pH} 2$ to over 100 at $\mathrm{pH} 9$ because of the different sensitivity of injection rate to $\mathrm{pH}$ for these materials. For $\mathrm{ReC} 1 \mathrm{P}$ on $\mathrm{TiO}_{2}$, the adsorbate excited-state oxidation potential is near the band edge, falling in the range in which the injection rate depends exponentially on the band edge position. For ReC1P on $\mathrm{SnO}_{2}$, the $0.5 \mathrm{~V}$ lower conduction band edge puts the system in an energetic range in which the injection rate depends much less sensitively on $\mathrm{pH}$. To gain further insight into the semiconductor dependence of electron injection rate, the band edge position difference should be accounted for. To do that, we have fitted the measured ET rates as a function of the $\mathrm{pH}$-dependent conduction band edge position for each system using eq 5. Shown in Figure 12 is a comparison of these rates and their fits for $\mathrm{ReC} 1 \mathrm{P}$ on $\mathrm{TiO}_{2}$ and $\mathrm{SnO}_{2}$. The $H_{0}$ values used for the fit are 100 and $350 \mathrm{~cm}^{-1}$ for $\mathrm{TiO}_{2}$ and $\mathrm{SnO}_{2}$, respectively.

For ReC1P, the adsorbate excited-state oxidation potential is near the band edge of $\mathrm{TiO}_{2}$, but is significantly above that of $\mathrm{SnO}_{2}$. Although at $\mathrm{pH}>2$, faster ET rates to $\mathrm{SnO}_{2}$ than to $\mathrm{TiO}_{2}$ were observed, the model predicts that, at lower $\mathrm{pH}$, such as $\mathrm{pH} 0$, injection rate to $\mathrm{TiO}_{2}$ would become faster. Indeed, the measured injection rate to $\mathrm{TiO}_{2}$ at $\mathrm{pH}=0$ is significantly faster than those to $\mathrm{SnO}_{2}$ at $\mathrm{pH}=2-9$. Despite weaker electronic coupling to $\mathrm{TiO}_{2}$, when $E_{\mathrm{ox}}$ is sufficiently above the conduction band edge, the much larger density of conduction states leads to a larger injection rate in this system. In a previous comparison of injection rate in $\mathrm{RuN} 3$ sensitized $\mathrm{TiO}_{2}$ and $\mathrm{SnO}_{2}$, we have estimated from the fast ( $<100 \mathrm{fs}$ ) injection component amplitude that the injection rate from the unthermalized excited state is more than 10 times faster in $\mathrm{TiO}_{2}$, consistent with the ratio predicted here. ${ }^{43,85}$ Recent experimental results from our group also indicated that using organic dyes with an oxidation potential more negative than $-1 \mathrm{~V}$ (vs SCE), such as coumarin 343 , electron injection rate to $\mathrm{TiO}_{2}$ is more than 10 times faster than that to $\mathrm{SnO}_{2}{ }^{86}$

It is evident from the above comparisons that the model described by eq 5 provides a useful way to understand the dependence of injection rate on $\mathrm{pH}$, anchoring group, and semiconductor. It should be emphasized that this simple model involves many assumptions that should be further tested. The essential feature of the model is that the relevant density of electron-accepting states has a dependence on energy similar to the bulk density of states, exhibiting a slow $\left(\sim E^{1 / 2}\right)$ increase above and an exponential variation below the conduction band edge. This is likely a reasonable qualitative description of DOS shape near the band edge for many semiconductor nanomaterials that are not in the quantum-confined size regime. However, the quantitative DOS value given by eq 4 is likely not accurate. As a result, the value of $H_{0}$ obtained from the fit should be only considered as approximate.

\section{Conclusion}

Photoinduced electron injection from $\mathrm{ReC} 1 \mathrm{~A}$ to $\mathrm{TiO}_{2}$ and $\mathrm{ReC} 1 \mathrm{P}$ to $\mathrm{SnO}_{2}$ and $\mathrm{TiO}_{2}$ were measured as a function of $\mathrm{pH}$. For ReC1P on $\mathrm{TiO}_{2}$, injection rate changed by 3 orders of magnitude from $\mathrm{pH}=0-9$. A similarly sensitive dependence on $\mathrm{pH}$ was also observed for $\mathrm{ReC} 1 \mathrm{~A} / \mathrm{TiO}_{2}$. For $\mathrm{ReC} 1 \mathrm{P}$ on $\mathrm{SnO}_{2}$, the injection rate varied by a factor of 4 from $\mathrm{pH} 2-9$, showing a much smaller $\mathrm{pH}$ dependence. By comparing with Marcus' theory of interfacial ET, the $\mathrm{pH}$ dependence can be accounted for qualitatively by the $-60 \mathrm{mV} / \mathrm{pH}$ variation of conduction band edge position. The sensitive $\mathrm{pH}$ dependence on $\mathrm{TiO}_{2}$ is a result of the proximity of adsorbate excited-state potential with the conduction band edge, at which the density of electronaccepting state changes sensitively with band edge position. The smaller dependence on $\mathrm{SnO}_{2}$ can be attributed to its $\sim 0.5 \mathrm{~V}$ lower conduction band edge position, for which the density of electron-accepting states, located further above the band edge, showed a much smaller variation with $\mathrm{pH}$. The injection rate to $\mathrm{TiO}_{2}$ from $\mathrm{ReC} 1 \mathrm{P}$ was found to be $\sim 10$ times larger than from $\mathrm{ReC} 1 \mathrm{~A}$, which was attributed to a stronger electronic coupling strength in the former. For ReC1P, its relative injection rate to $\mathrm{TiO}_{2}$ and $\mathrm{SnO}_{2}$ depends sensitively on the $\mathrm{pH}$ of the solution, reflecting the different $\mathrm{pH}$ dependence in these systems.

Acknowledgment. This work is funded by US DOE, Office of Science (grant nos. DE-FG02-87ER13808 to J.H., and DEFG02-98ER14918 to T.L.). T.L. acknowledges the partial financial support by the donors of the Petroleum Research Fund, Emory University Research Committee, and the Alfred P. Sloan Foundation. Z.Q.T. and T.L. thank the financial support of the National Science Foundation of China (grant no. 20228020).

Supporting Information Available: Graphs showing: transient IR absorption spectra of $\mathrm{ReC} 1 \mathrm{P} / \mathrm{TiO}_{2}$ and $\mathrm{ReC} 1 \mathrm{~A} / \mathrm{TiO}_{2}$ in varying $\mathrm{pH}$ after $400 \mathrm{~nm}$ excitation; comparison of the growth kinetics of the IR absorption of injected electrons probed at 2140 $\mathrm{cm}^{-1}$ and $2120 \mathrm{~cm}^{-1}$ and the oxidized adsorbate CO stretching peak area at $\sim 2095 \mathrm{~cm}^{-1}$ and $\sim 2085 \mathrm{~cm}^{-1}$ for $\mathrm{ReC} 1 \mathrm{P} / \mathrm{TiO}{ }_{2}$ and $\mathrm{ReC} 1 \mathrm{~A} / \mathrm{TiO}_{2}$, respectively, at varying $\mathrm{pH}$. This material is available free of charge via the Internet at http://pubs.acs.org.

\section{References and Notes}

(1) Miller, R. J. D.; McLendon, G. L.; Nozik, A. J.; Schmickler, W.; Willig, F. Surface Electron-Transfer Processes; VCH Publishers: New York, 1995 
(2) See Coord. Chem. Rev. 2004, 248, (Michael Graetzel Festschrift).

(3) Hagfeldt, A.; Gratzel, M. Chem. Rev. 1995, 95, 49.

(4) Moser, J. E.; Bonnote, P.; Gratzel, M. Coord. Chem. Rev. 1998, 171,245 .

(5) Nitzan, A.; Ratner, M. A. Science 2003, 300, 1384.

(6) Nitzan, A. J. Phys. Chem. A 2001, 105, 2677.

(7) Adams, D. M.; Brus, L.; Chidsey, C. E. D.; Creager, S.; Creutz, C.; Kagan, C. R.; Kamat, P. V.; Lieberman, M.; Lindsay, S.; Marcus, R. A.; Metzger, R. M.; Michel-Beyerle, M. E.; Miller, J. R.; Newton, M. D.; Rolison, D. R.; Sankey, O.; Schanze, K. S.; Yardley, J.; Zhu, X. J. Phys. Chem. B 2003, 107, 6668.

(8) Marcus, R. A. J. Chem. Phys. 1965, 43, 679.

(9) Gao, Y. Q.; Georgievskii, Y.; Marcus, R. A. J. Chem. Phys. 2000, 112,3358

(10) Gao, Y. Q.; Marcus, R. A. J. Chem. Phys. 2000, 113, 6351.

(11) Gosavi, S.; Marcus, R. A. J. Phys. Chem. B 2000, 104, 2067.

(12) Pankove, J. I. Optical Processes in Semiconductors; Dover: New York, 1975.

(13) Semiconductor Electrodes; Finklea, H. O., Ed.; Elsevier: New York, 1988; Vol. 55

(14) Watanabe, T.; Fujishima, A.; Honda, K. Chem. Lett. 1974, 8, 897.

(15) Watanabe, T.; Fujishima, A.; Tatsuoki, O.; Honda, K. Bull. Chem. Soc. Jpn. 1976, 49, 8.

(16) Lyon, L. A.; Hupp, J. T. J. Phys. Chem. B 1999, 103, 4623.

(17) Boschloo, G.; Fitzmaurice, D. J. Phys. Chem. B 1999, 103, 2228.

(18) Rothenberger, G.; Fitzmaurice, D.; Gratzel, M. J. Phys. Chem. 1992, 96, 5983.

(19) Lemon, B. I.; Liu, F.; Hupp, J. T. Coord. Chem. Rev. 2004, 248, 1225 .

(20) Boxall, C. Chem. Soc. Rev. 1994, 23, 137

(21) Moser, J.; Gratzel, M. J. Am. Chem. Soc. 1983, 105, 6547.

(22) Zaban, A.; Ferrere, S.; Sprague, J.; Gregg, B. A. J. Phys. Chem. B

$1997,101,55$

(23) Gaal D. A.; Hupp J. T. In Semiconductor Photochemistry and Photophysics (Molecular and Supramolecular Photochemistry, 10); Schanze, K. S., Ramamurthy, V., Eds.; Marcel Dekker: New York, 2002; Vol. 10; p 89.

(24) Clark, W. D. K.; Sutin, N. J. Am. Chem. Soc. 1977, 99, 4676.

(25) Sonntag, L. P.; Spitler, M. T. J. Phys. Chem. 1985, 89, 1453.

(26) Watson, D. F.; Marton, A.; Stux, A. M.; Meyer, G. J. J. Phys. Chem. B 2004, 108, 11680.

(27) Yan, S. G.; Hupp, J. T. J. Phys. Chem. 1996, 100, 6867.

(28) Gaal, D. A.; Hupp, J. T. J. Am. Chem. Soc. 2000, 122, 10956.

(29) Martini, I.; Hodak, J. H.; Hartland, G. V. J. Phys. Chem. B 1998, $102,607$.

(30) Gaal, D. A.; Hupp, J. T. J. Am. Chem. Soc. 2000, 122, 10956.

(31) Nelson, J.; Haque, S. A.; Klug, D. R.; Durrant, J. R. Phys. Rev. B: Condens. Matter Mater. Phys. 2001, 63, 205321.

(32) Nelson, J. Phys. Rev. B: Condens. Matter Mater. Phys. 1999, 59,

(33) Barzykin, A. V.; Tachiya, M. J. Phys. Chem. B 2004, 108, 8385.

(34) Barzykin, A. V.; Tachiya, M. J. Phys. Chem. B 2002, 106, 4356.

(35) Qu, P.; Meyer, G. J. Langmuir 2001, 17, 6720.

(36) Asbury, J. B.; Anderson, N. A.; Hao, E.; Lian, T. J. Phys. Chem. B 2003, 107, 7376.

(37) Anderson, N. A.; Lian, T. Coord. Chem. Rev. 2004, 248, 1231.

(38) Anderson, N. A.; Ai, X.; Chen, D.; Mohler, D. L.; Lian, T. J. Phys. Chem. B 2003, 107, 14231.

(39) Wang, Y.; Asbury, J. B.; Lian, T. J. Phys. Chem. A 2000, 104, 4291.

(40) Asbury, J. B.; Hao, E.; Wang, Y.; Lian, T. J. Phys. Chem. B 2000, 104, 11957.

(41) Guo, J.; She, C.; Lian, T. J. Phys. Chem. B. 2005, 109, 7095.

(42) Nutz, T.; Felde, U. Z.; Haase, M. J. Chem. Phys. 1999, 110, 12142.

(43) Ai, X.; Anderson, N. A.; Guo, J.; Lian, T. J. Phys. Chem. B 2005, 109, 7088 .

(44) Walters, K. A.; Gaal, D. A.; Hupp, J. T. J. Phys. Chem. B 2002, 106,5139

(45) Yan, S. G.; Prieskorn, J. S.; Kim, Y.; Hupp, J. T. J. Phys. Chem. B 2000, 104, 10871 .

(46) Worl, L. A.; Duesing, R.; Chen, P.; Ciana, L. D.; Meyer, T. J. J. Chem. Soc., Dalton Trans. 1991, 849.

(47) Nazeeruddin, M. K.; Zakeerudin, S. M.; Humphry-Baker, R.; Jirousek, M.; Liska, P.; Vlachopoulos, N.; Shklover, V.; Fischer, C.-H.; Gratzel, M. Inorg. Chem. 1999, 38, 6298.
(48) Yan, S. G.; Hupp, J. T. J. Phys. Chem. B 1997, 101, 1493

(49) Pechy, P.; Rotzinger, F. P.; Nazeeruddin, M. K.; Kohle, O.; Zakeeruddin, S. M.; Humphry-Baker, R.; Gratzel, M. J. Chem. Soc., Chem. Commun. 1995, 65.

(50) Zakeeruddin, S. M.; Nazeeruddin, M. K.; Pechy, P.; Rotzinger, F P.; Humphry-Baker, R.; Kalyanasundaram, K.; Gratzel, M.; Shklover, V.; Haibach, T. Inorg. Chem. 1997, 36, 5937.

(51) Gillaizeau-Gauthier, I.; Odobel, F.; Alebbi, M.; Argazzi, R.; Costa, E.; Bignozzi, C. A.; Qu, P.; Meyer, G. J. Inorg. Chem. 2001, 40, 6073.

(52) Zabri, H.; Gillaizeau, I.; Bignozzi, C. A.; Caramori, S.; Charlot, M.-F.; Cano-Boquera, J.; Odobel, F. Inorg. Chem. 2003, 42, 6655.

(53) Bae, E.; Choi, W.; Park, J.; Shin, H. S.; Kim, S. B.; Lee, J. S. J. Phys. Chem. B. 2004, 108, 14093.

(54) Nilsing, M.; Lunell, S.; Persson, P.; Ojamaee, L. Surf. Sci. 2005, $582,49$.

(55) Asbury, J. B.; Wang, Y.; Lian, T. Bull. Chem. Soc. Jpn. 2002, 75, 973.

(56) Dattelbaum, D. M.; Meyer, T. J. J. Phys. Chem. A 2002, 106, 4519. (57) Zaban, A.; Ferrere, S.; Gregg, B. A. J. Phys. Chem. B 1998, 102, 452.

(58) Lenchenkov, V. A.; She, C.; Lian, T. J. Phys. Chem. B 2004, 108, 16194

(59) George, M. W.; Turner, J. J. Coord. Chem. Rev. 1998, 177, 201.

(60) Turner, J. J.; George, M. W.; Johnson, F. P. A.; Westwell, J. R. Coord. Chem. Rev. 1993, 125, 101.

(61) Gamelin, D. R.; George, M. W.; Glyn, P.; Grevels, F. W.; Johnson, F. P. A.; Klotzbucher, W.; Morrison, S. L.; Russell, G.; Schaffner, K. Turner, J. J. Inorg. Chem. 1994, 33, 3246.

(62) Clark, I. P.; George, M. W.; Johnson, F. P. A.; Turner, J. J. Chem. Commun. (Cambridge) 1996, 1587.

(63) Ellingson, R. J.; Asbury, J. B.; Ferrere, S.; Ghosh, H. N.; Sprague, J. R.; Lian, T.; Nozik, A. J. J. Phys. Chem. B 1998, 102, 6455.

(64) Asbury, J. B.; Ellingson, R. J.; Ghosh, H. N.; Ferrere, S.; Nozik, A. J.; Lian, T. J. Phys. Chem. B 1999, 103, 3110.

(65) Benko, G.; Kallioinen, J.; Korppi-Tommola, J. E. I.; Yartsev, A. P.; Sundstrom, V. J. Am. Chem. Soc. 2002, 124, 489

(66) Kallioinen, J.; Benko, G.; Sundstrom, V.; Korppi-Tommola, J. E.

I.; Yartsev, A. P. J. Phys. Chem. B 2002, 106, 4396.

(67) Hannappel, T.; Burfeindt, B.; Storck, W.; Willig, F. J. Phys. Chem. B 1997, 101, 6799 .

(68) Tachibana, Y.; Moser, J. E.; Graetzel, M.; Klug, D. R.; Durrant, J. R. J. Phys. Chem. 1996, 100, 20056

(69) Kuciauskas, D.; Monat, J. E.; Villahermosa, R.; Gray, H. B.; Lewis,

N. S.; McCusker, J. K. J. Phys. Chem. B 2002, 106, 9347.

(70) Montalti, M.; Wadhwa, S.; Kim, W. Y.; Kipp, R. A.; Schmehl, R. H. Inorg. Chem. 2000, 39, 76.

(71) Santos, L. R. B.; Larbot, A.; Santilli, C. V.; Pulcinelli, S. H. J. Sol-Gel Sci. Technol. 1998, 13, 805 .

(72) Henrich, V.; Cox, P. The Surface Science of Metal Oxides; Cambridge University Press: Cambridge, 1996.

(73) Vittadini, A.; Selloni, A.; Rotzinger, F. P.; Gratzel, M. J. Phys.

Chem. B. 2000, 104, 1300

(74) Zhu, X. Y. Аnnu. Rev. Phys. Chem. 2002, 53, 221.

(75) Harris, C. B.; Ge, N. H.; Lingle, R. L.; McNeill, J. D.; Wong, C. M. Annu. Rev. Phys. Chem. 1997, 48, 711.

(76) Sakata, T.; Hashimoto, K.; Hiramoto, M. J. Phys. Chem. 1990, 94, 3040 .

(77) Nelson, J.; Kirkpatrick, J.; Ravirajan, P. Phys. Rev. B: Condens. Matter 2004, 69, 035337.

(78) Willis, R. L.; Olson, C.; O’Regan, B.; Lutz, T.; Nelson, J.; Durrant,

J. R. J. Phys. Chem. B 2002, 106, 7605.

(79) Morigaki, K. Physics of Amorphous Semiconductors; Imperial College Press: London, 1999.

(80) Enright, B.; Fitzmaurice, D. J. Phys. Chem. 1996, 100, 1027.

(81) Redmond, G.; Fitzmaurice, D.; Graetzel, M. J. Phys. Chem. 1993, 97, 6951 .

(82) Kelly, C. A.; Farzad, F.; Thompson, D. W.; Stipkala, J. M.; Meyer, G. J. Langmuir 1999, 15, 7047.

(83) Tachibana, Y.; Haque, S. A.; Mercer, I. P.; Moser, J. E.; Klug, D. R.; Durrant, J. R. J. Phys. Chem. B 2001, 105, 7424.

(84) Yaliraki, S. M.; Kemp, M.; Ratner, M. A. J. Am. Chem. Soc. 1999, 121,3428

(85) Ai, X.; Guo, J.; Anderson, N. A.; Lian, T. J. Phys. Chem. B 2004, $108,12795$.

(86) Stockwell, D.; El-Sayed Mostafa, A.; Lian, T. to be published. 